University of Louisville ThinkIR: The University of Louisville's Institutional Repository

Electronic Theses and Dissertations

$5-2016$

\title{
Modification of T9SS cargo proteins of Porphyromonas gingivalis for their secretion in soluble form and purification by affinity chromatography.
}

Apoorv Goel

University of Louisville

Follow this and additional works at: https://ir.library.louisville.edu/etd

Part of the Oral Biology and Oral Pathology Commons

\section{Recommended Citation}

Goel, Apoorv, "Modification of T9SS cargo proteins of Porphyromonas gingivalis for their secretion in soluble form and purification by affinity chromatography." (2016). Electronic Theses and Dissertations. Paper 2415.

https://doi.org/10.18297/etd/2415

This Master's Thesis is brought to you for free and open access by ThinkIR: The University of Louisville's Institutional Repository. It has been accepted for inclusion in Electronic Theses and Dissertations by an authorized administrator of ThinkIR: The University of Louisville's Institutional Repository. This title appears here courtesy of the author, who has retained all other copyrights. For more information, please contact thinkir@louisville.edu. 


\title{
MODIFICATION OF T9SS CARGO PROTEINS OF PORPHYROMONAS GINGIVALIS FOR THEIR SECRETION IN SOLUBLE FORM AND PURIFICATION BY AFFINITY CHROMATOGRAPHY
}

\author{
By \\ Apoorv Goel \\ B.D.S., Pt. B.D. Sharma University of Health Sciences (INDIA), 2013
}

\begin{abstract}
A Thesis
Submitted to the Faculty of the School of Dentistry of the University of Louisville

In Partial Fulfillment of the Requirements For the Degree of
\end{abstract}

Master of Science

In Oral Biology

Department of Oral Immunology and Infectious Diseases

School of Dentistry University of Louisville Louisville, Kentucky

May 2016 
Copyright 2016 by Apoorv Goel

All Rights Reserved 



\title{
MODIFICATION OF T9SS CARGO PROTEINS OF PORPHYROMONAS GINGIVALIS FOR THEIR SECRETION IN SOLUBLE FORM AND PURIFICATION BY AFFINITY CHROMATOGRAPHY
}

\author{
By \\ Apoorv Goel \\ B.D.S., Pt. B.D. Sharma University of Health Sciences (INDIA), 2013
}

A Thesis Approved on

April $19^{\text {th }} 2016$

By the following Thesis Committee:

Jan S. Potempa, Ph.D., D.Sc.

Thesis Director

Richard J. Lamont, Ph.D.

Committee Member

David A. Scott, Ph.D.

Committee Member

Silvia M. Uriarte, Ph.D.

Committee Member 


\section{DEDICATION}

This thesis is dedicated to my parents Mr. Ashwani Goel and Mrs. Lata Goel

for their support, encouragement and unconditional love, and also to

my brother Mr. Akshat Goel for giving direction to my life. 


\section{ACKNOWLEDGEMENTS}

I am using this opportunity to express my gratitude to everyone who supported me during my journey of attaining my Masters of Science degree.

First and foremost I offer my sincerest gratitude to my mentor Dr. Jan S. Potempa for his valuable guidance and patience in teaching me the basics of scientific research. I cannot thank him enough for sharing his insight and expertise, which has greatly helped me in developing my career as a future researcher and a critical thinker. It was an honor to work under the guidance of the most humble teacher I have ever worked with.

I would like to thank my committee members, Dr. Richard J. Lamont, Dr. David A. Scott and Dr. Silvia M. Uriarte for their valuable input and suggestions throughout my master's degree. Their collective knowledge, guidance and setting the direction for the project is highly appreciated. Thank you for your time and patience.

I would like to thank Dr. Anna Lasica and Mrs. Barbara Potempa for their valuable guidance, support, and technical expertise. All the credit for my growth as a researcher goes to them. With so much to say and no words to express, a big wholehearted thank you for making me capable enough to defend my master's degree. This journey would not have been possible without both of them.

I would also like to thank Dr. Douglas Darling, Program Director (Oral Biology) for giving me this opportunity and for his assistance over the past two years. My sincere 
thanks go to Mr. Ed Thompson and Mr. Gerard Buono for being part of my journey and providing administrative support.

This acknowledgement would not be complete without mentioning the support and love from my family and friends. Special thanks goes to my sister, Varsha Goel for making me believe that the impossible is possible and to have a positive attitude towards life. I would like to thank my lab members, Lahari and Apurva, for their friendship and support as blossomed with time. Special thanks to my friends, Ankur Gupta, Nawar Sileewa, Mayank Sharma, Tanvi Rehani and Ankit Pahuja for supporting me always. 


\begin{abstract}
MODIFICATION OF T9SS CARGO PROTEINS OF PORPHYROMONAS GINGIVALIS FOR THEIR SECRETION IN SOLUBLE FORM AND PURIFICATION BY AFFINITY CHROMATOGRAPHY
\end{abstract}

Apoorv Goel

April 19, 2016

Background: Porphyromonas gingivalis, a keystone-pathogen associated with periodontitis, utilizes the Type IX Secretion System (T9SS) to secrete proteins bearing the conserved C-terminal domain (CTD), many of which are essential virulence factors. These include, beside gingipains and PPAD, 29 other proteins. During or after the outer membrane translocation the CTD is cleaved off and a glycan moiety is covalently attached anchoring the secreted proteins at the bacterial cell surface. Objective: Most of the CTD bearing proteins have only hypothetical functions assigned. It is plausible that these CTD bearing proteins may also play a crucial role in $P$. gingivalis pathogenesis. Therefore, it would be of interest to determine their precise role, which could be accomplished through protein purification and subsequent characterization. Three CTD proteins were chosen as first targets: C25 peptidase (PG_RS01820), Carboxypeptidase D (PG_RS01060; Cpg70) and Periodontain (PG_RS06260; PrtT related). Methods: It was shown previously that the insertion of a hexahistidine affinity 
tag upstream of the CTD in RgpB and PPAD results in secretion of soluble, nonglycosylated, mature forms of these enzymes into the culture media, this facilitates their purification by nickel-chelate affinity chromatography. This same approach was applied in the present study. Results: Isogenic mutant strains of $P$. gingivalis with the insertion of a hexahistidine affinity tag upstream of the CTD were generated via homologous recombination. The presence of soluble proteins bearing the hexahistidine tag in growth media were confirmed for carboxypeptidase D (CPG70) and periodontain (PrtT related) expressing strains. These two proteins were then purified to homogeneity by Ni-Sepharose affinity chromatography. Conclusion: Purification of two CTD bearing proteins out of three chosen targets, confirmed that the applied method can be successfully used for purification of other proteins from this family. In the case of C25 peptidase the failure to find the His-tagged protein can be due to very low expression level. 


\section{TABLE OF CONTENTS}

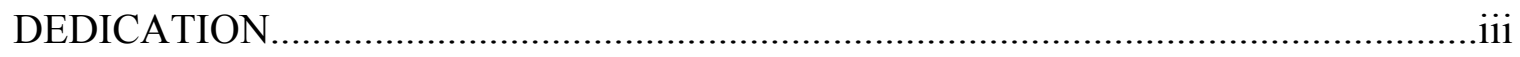

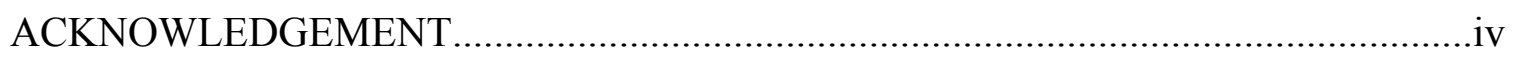

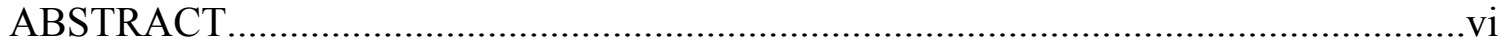

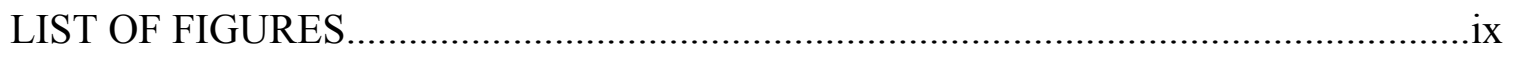

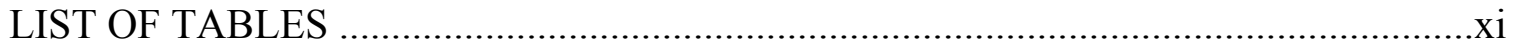

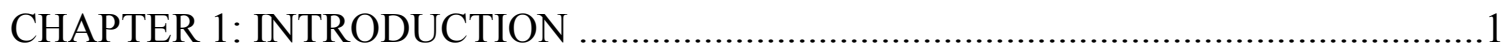

CHAPTER 2: RESEARCH HYPOTHESIS AND SPECIFIC AIMS ..........................18

CHAPTER 3: MATERIALS AND METHODS ...........................................................20

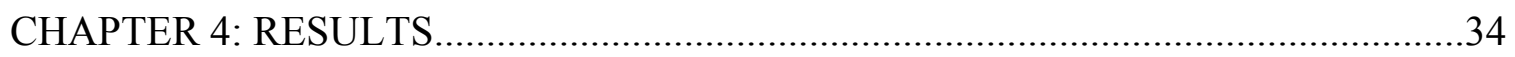

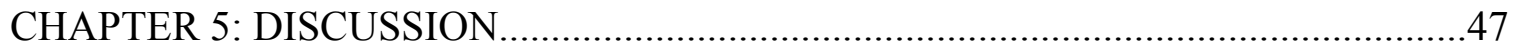

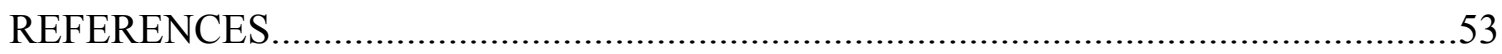

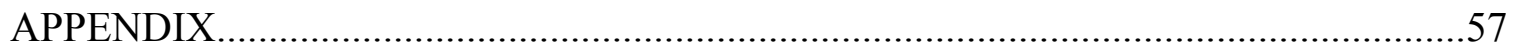

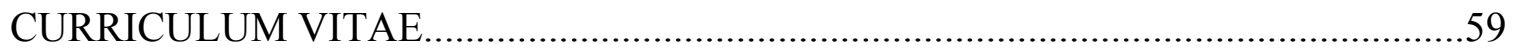




\section{LIST OF FIGURES}

FIGURE

PAGE

1. Schematic overview of the Escherichia coli Sec- and Tat translocases............4

2. Schematic representation of final subcellular localizations of secreted proteins in diderm (Gram-negative) bacteria in relation to the translocation systems involved......................................5

3. Model of the T9SS (type IX secretion system) of $P$. gingivalis..........................14

4. The structure-based alignment of the CTD of proteins secreted by P. gingivalis via T9SS................................................ 15

5. Schematic diagram of RgpB produced by $P$. gingivalis ....................... 17

6. Schematic view of the domain structure of T9SS cargo proteins.................19

7. One kb DNA Ladder (Thermo Scientific) ............................... 25

8. Precision Plus Protein Kaleidoscope Protein Ladder..........................33

9. Schematic view of construction of the PG_RS06260 master plasmid pAG3 .......36

10. Schematic view of the master plasmid pAG5 (for gene PG_RS01820)..........37

11. Schematic view of the master plasmid pCpgCeB (for gene PG_RS01060).......38

12. Alignment of sequences of W83 vs. AG002 (a fragment).....................41

13. Western-blot analysis of fractions obtained from $P$. gingivalisAG002-AG006 cultures theoretically expressing His-tagged Periodontain (AG002 and AG003) C25 peptidase (AG004 and AG005) and CPG70 (AG006) 
FIGURE

14. Western-blot analysis of elution samples obtained after purification of AG002 and AG003 (Periodontain), AG004 and AG005 (C25 peptidase) and AG006 (CPG70) from culture media of the mutant strains

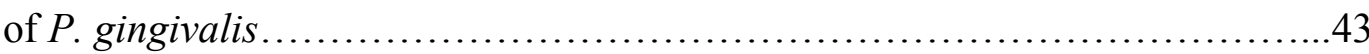

15. SDS-PAGE and Western Blots analyses of full purification process for AG002 and AG003 (Periodontain), AG004 and AG005 (C25 peptidase) and AG006 (CPG70) strains of $P$. gingivalis..............................46 


\section{LIST OF TABLES}

TABLE

PAGE

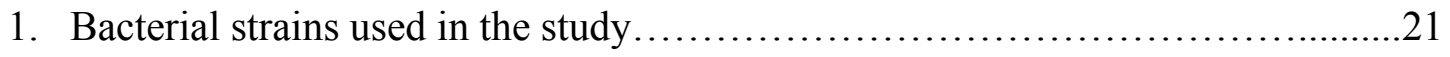

2. The PCR program used to amplify different fragments of $P$. gingivalis $\mathrm{W} 83$

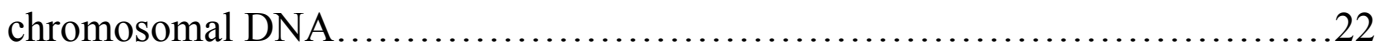

3. Primers used for the amplification of gene of interest..........................23

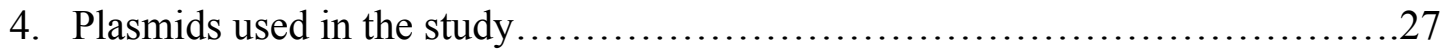

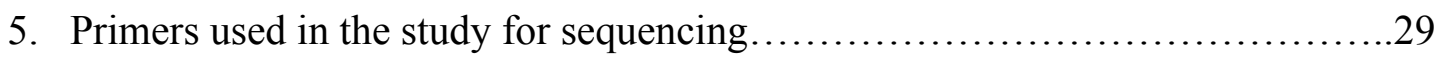

6. Phosphorylated primers used to insert 6His tags in the plasmids..................30

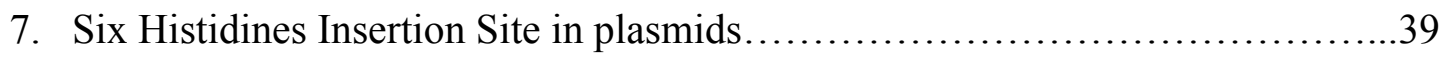

8. Mutants via homologous recombination....................................40 


\section{CHAPTER 1}

\section{INTRODUCTION}

All proteins are synthesized in the cytoplasm of a living cell and then distributed to various subcellular departments or are sent out of the cell. The cytoplasm and the external environment of the cell are separated by a lipid bilayer, a so-called biological membrane. It is this membrane that acts as a barrier for the passage of the proteins outside the cell. To allow the passage of the proteins and other macromolecules across the cell membrane without compromising its function and structure various mechanisms of transport have evolved.

With respect to the transport of proteins, 'protein secretion' in prokaryote is a process involving active transport of proteins across the cell envelope to the extracellular environment. In Gram-negative didermal bacteria with the cell envelope composed of the inner membrane (IM) and the outer membrane (OM) with the periplasmic space, the term "secretion" is reserved for the active process, which places proteins completely outside the cell after they pass the outermost lipid layer (OM). In contrast to secretion, 'protein export' is an active transport of proteins from cytoplasmic space across the IM into the periplasm. In the case of monoderm bacteria (gram positive bacteria), 'protein export' is synonymous with 'protein secretion'.

The secreted proteins have been found to fulfill various functions in processes such as acquisition of nutrients, motility, adhesion and intracellular communication. They 
have also been found to play the role in the virulence of the organism by compromising the host immune system. Many bacteria such as Staphylococcus aureus secrete toxins into the extracellular milieu during infection that damages host cell membranes [1]. These substrates are diffused within the extracellular fluids but their concentration is found to be highest in the close vicinity of staphylococci [1]. Other toxins released from the invading pathogen can act at a distance as well. This is how the toxins or proteins secreted can play a role as virulence factors of the bacterium. Another example to show the role played by secreted proteins is gingipains that are secreted by Porphyromonas gingivalis. Gingipains play a role in adherence to and colonization of epithelial cells, disrupting and manipulating inflammatory response, hemolysis of erythrocytes and degradation of host tissues [2].

\section{Secretion across the cytoplasmic membrane}

The first barrier any protein will face when trying to exit a bacterial cell will be the cytoplasmic membrane (IM), regardless of whether the bacterium is Gram-positive or negative. To allow the passage of the protein through the cytoplasmic membrane without compromising its structure and function, they may take either Sec (general secretory, or GSP), or Tat (twin-arginine translocation) pathways.

In bacteria, the Sec pathway is found to be responsible for the export of most extracellular proteins, which play crucial role in sensing, cell communication, metabolism, cell envelope structure and substrate uptake and excretion [1]. Secretory proteins are targeted to Sec translocase by two mechanisms, post-translational and cotranslational targeting. During post-translational targeting, the translated polypeptides 
bearing an N-terminal signal sequence (signal peptide) are released from the ribosome and then directed to Sec-translocase [3] by the secretion specific chaperone $\mathrm{SecB}$, that keeps proteins in the unfolded state (as shown in figure 1) [3]. During co-translational targeting, a signal sequence is released from ribosome before completion of the translation and binds to SRP (signal-recognition particle) to form a complex: SRPribosome-nascent secretory protein (as shown in figure 1) and targeted through FtsY receptor to the Sec-translocase [3]. This pathway is mostly responsible for inserting proteins into the cytoplasmic membrane and less often for the protein secretion. In both pathways translocation across the IM occurs through a membrane-embedded proteinconducting channel (PCC). PCC consists of three important proteins SecY, SecE and SecG, and a peripheral associated ATPase, SecA, which drives the translocation of secretory proteins across the membrane (Figure 1) [3]. The energy required for the process is attained from ATP and the proton-motive force (PMF).

Unlike the Sec pathway, the Tat pathway has a specialized and unique function of transporting across the cytoplasmic membrane proteins that are already folded. Proteins that are exported through the Tat pathway consists of an $\mathrm{N}$-terminal signal peptide that directs the proteins to the Tat apparatus (Figure 1) [3]. These signal peptides have a pair of adjacent arginine residues, hence called twin-arginine translocation pathway (Tat). The energy required by this pathway to transport the proteins is achieved from PMF [4]. 


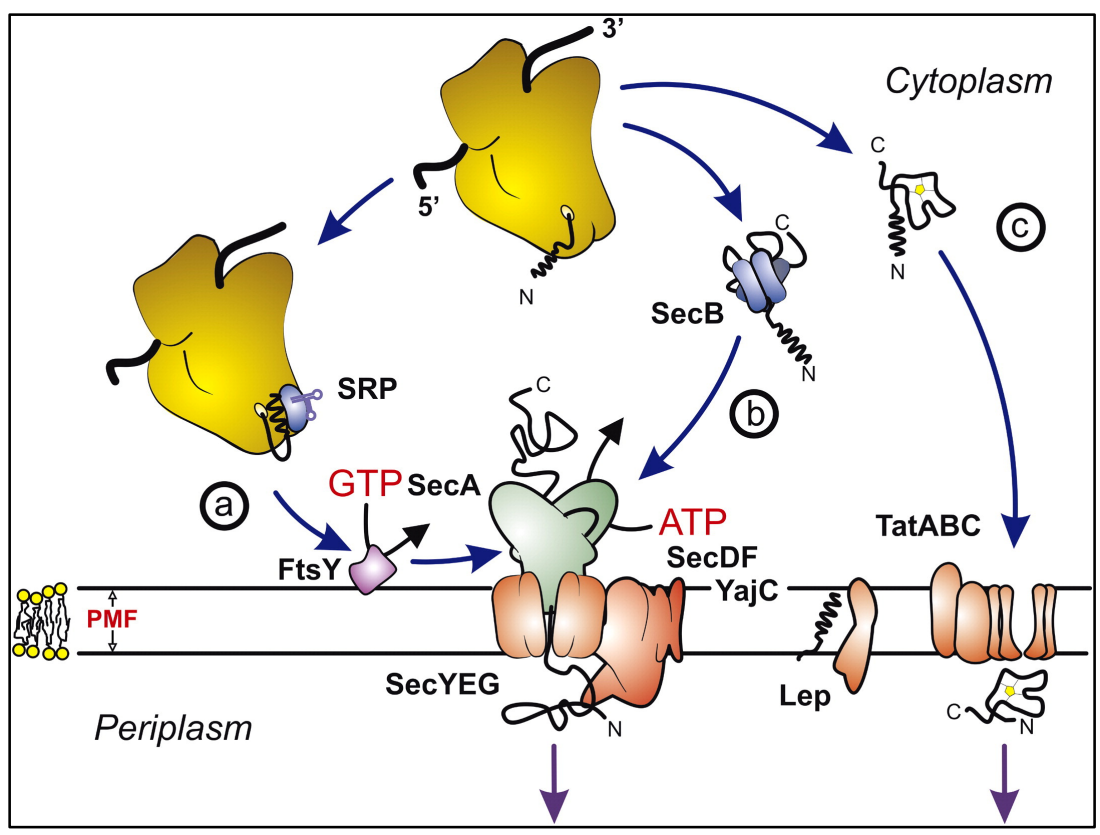

Figure 1. Schematic overview of the Escherichia coli Sec- and Tat translocases.

(a) Co-translational and (b) post-translational targeting routes and translocation of unfolded proteins by the Sec-translocase. (c) Translocation of folded precursor proteins by the Tat translocase. Adapted from Natale, Brüser [3].

Monoderm bacteria that consist of only one membrane (cytoplasmic membrane) mostly use either Sec-dependent or Tat-dependent pathways to secrete the proteins outside the cells. In such cases, protein secretion is synonymous to the protein export, unlike in cases with didermal bacteria, with two membranes (inner and outer membrane).

\section{Protein Secretion in Diderm Bacteria (gram negative bacteria)}

In contrast to other bacteria, didermal bacteria, which are mostly Gram-negative bacteria, have in addition to the cytoplasmic membrane also called inner membrane (IM), outer membrane (OM). The $\mathrm{OM}$ is impermeable to proteins; thus, gram-negative bacteria have evolved various remarkable mechanisms for the secretion of proteins outside the 
cell. These mechanisms are further classified as eight unique Types (I to VIII) of Secretion systems (Schematic representation, figure 2), which either transport proteins across OM in a one-step manner (T1SS, T3SS, T4SS, and T6SS), or are first exported across the inner membrane into the periplasmic space (through Sec or Tat pathway) and then secreted out across the OM (T2SS, T4SS, T5SS, and T8SS). Depending on the secretion system, the secreted proteins have three possible fates: they remain associated with the bacterial outer membrane $(\mathrm{OM})$, they are released into the extracellular space/milieu, or they are injected into a target cell (either eukaryotic or bacterial cell) [5].

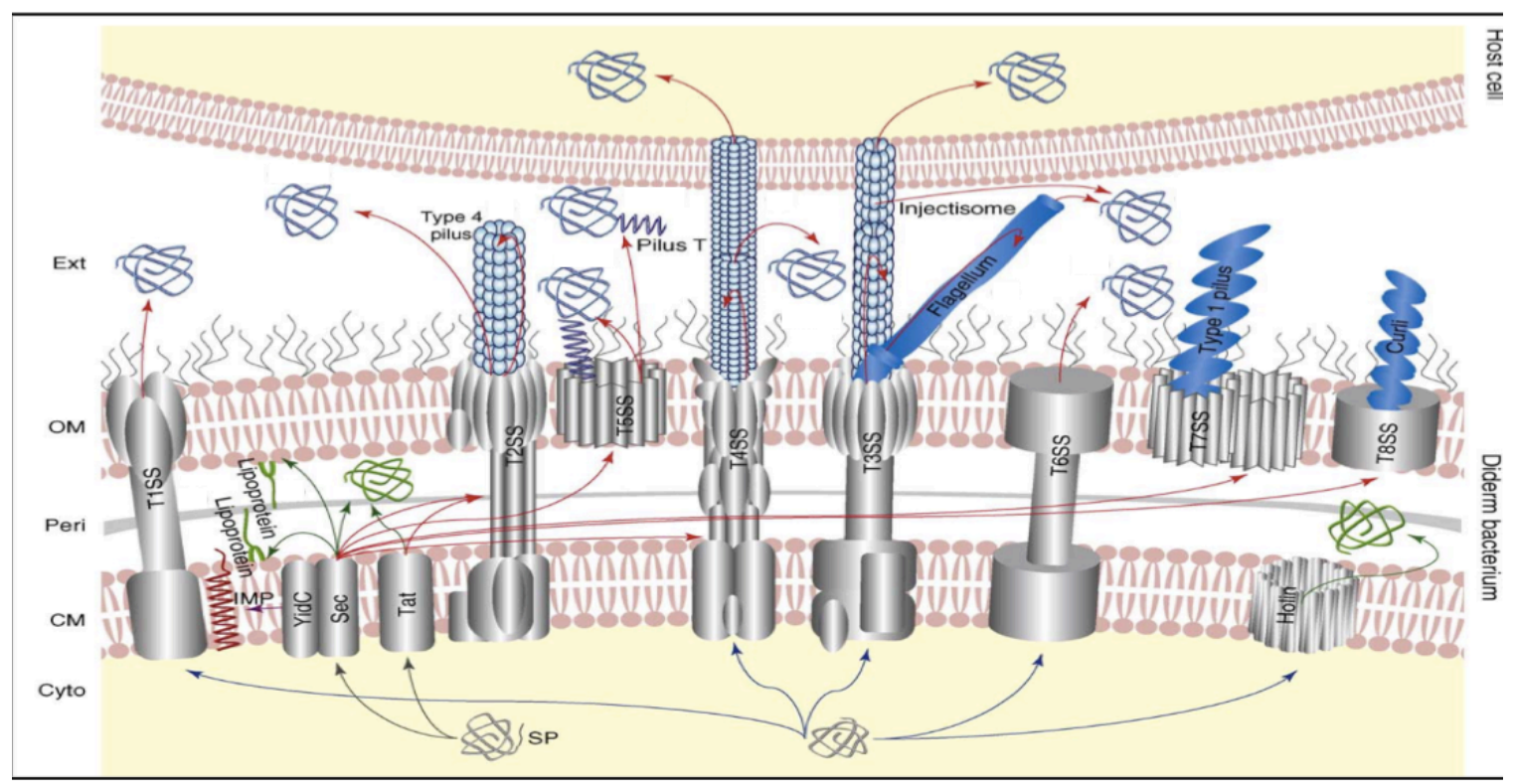

Figure 2. Schematic representation of final subcellular localizations of secreted proteins in diderm (Gram-negative) bacteria in relation to the translocation systems involved. Abbreviations: Cyto, cytoplasm; CM, cytoplasmic membrane; Peri, periplasm; OM, outer membrane; Ext, extracellular milieu. Modified and Adapted from Desvaux, Hebraud [6]. 


\section{Type I Secretion System (T1SS)}

T1SS allows the secretion of proteins from the cytoplasm across the outer membrane in a single step, bypassing the periplasmic compartment. The major components of T1SS are, ATP-binding cassette (ABC) transporters, Outer Membrane Factors (OMFs), and Membrane Fusion Proteins (MFP) [7]. Energy for secretion is provided through ATP hydrolysis; at the same time, additional structural components frame the complete protein secretion machinery across both outer and inner membrane. Structurally, OMFs form a trans-periplasmic channel penetrating the $\mathrm{OM}$ and are connected to MFP [8]. Proteins secreted by T1SS have a C-terminal signal sequence that is not cleaved off after secretion implying that the protein should be secreted in a post-translational fashion [7].

\section{Type II Secretion System (T2SS)}

T2SS is used by a wide variety of gram-negative bacteria to secrete their toxins and enzymes across the outer membrane. The proteins are secreted out in a two-step process, where protein export across the inner membrane is Sec-dependent and then the protein is secreted out through the T2SS machinery. The T2SS machinery consists of four parts, cytoplasmic ATPase, an IM platform, a periplasmic pseudophilus and an OM complex. The T2SS is composed of 12-15 secretin components, which are called general secretion pathway (GSP) proteins in E. coli, Eps in $V$. cholera, to mention few [9]. The pore is big enough to transport the folded proteins and the remaining 11-14 conserved components support in anchoring of the pore to the inner membrane and also include important periplasmic pseudopilin subunits [10]. The cytoplasmic ATPase may provide 
the energy that is required for the opening and closing of the secretin pore [9]. The T2SS machinery also possesses an inner membrane component, but it is only through Sec and Tat pathways, proteins are exported across the inner membrane.

\section{Type III Secretion System (T3SS)}

T3SS is an export machine, which is used by pathogenic gram-negative bacteria to transport proteins directly into the eukaryotic cytosol with the aim to modulate specific host cell functions, leading to bacterial invasion and colonization. One of the best-studied examples of T3SS is the one present in Salmonella typhimurium [11]. The T3SS consists of the 3.5 MDa multi-protein complex that spans through the entire bacterial envelope and acts as a main structural component of the system known as needle complex or 'injectisome' and consists of approximately 25 proteins that are arranged into 2 main substructures: a double-membrane-spanning base, composed of stacked rings, and a needle-like filament, which protrudes from the bacterial surface into the extracellular space [11-13]. T3SS also have cytosolic components that have the role in substrate recruitment; unfolding and also transport associate along with the base of the complex following contact with a host cell [13]. To transport these unfolded T3SS substrates efficiently through a needle-like filament, precise secretion signals have a role to play [13], which are generally encoded by the first 100 residues of the protein and that makes sure secretion processes in a hierarchical and coordinated manner [13]. The energy for the machinery is provided through conserved ATPase associated with the cytoplasmic base of injectisome and chaperones is responsible for the assembly of injectisome [12]. 


\section{Type IV Secretion System (T4SS)}

Type IV secretion systems (T4SSs) have a unique ability among the other secretion systems in that they can translocate DNA (in addition to proteins) both in a onestep and two-step manner. T4SSs are found in both gram-positive and gram-negative bacteria. T4SSs is very well explained in Agrobacterium tumefaciens, where T4SS is utilized to export transfer-DNA (t-DNA) into dicotyledonous plants, and the ssDNA, which is exported, have oncogenes, leads to tumor formation in the plant [14]. The major components of the T4SS in A. tumefaciens are VirB2-VirB11 and VirD4 [14]. The basic structure of T4SS consists of a core- outer membrane (OM) complex that is connected to a bipartite inner membrane (IM) complex through a central stalk $[8,14]$. The stalk is an elongated structure whose composition remains unknown. The system gets its energy by three ATPases: VirB4, VirB11 and VirD4 [15].

\section{Type V Secretion System (T5SS)}

The T5SSs, also known as an autotransporter system, are structurally different from other systems as in these systems the substrate and its secretion pore are fused together to form a single polypeptide, which in turn is able to carry out the secretion from the OM, by its own and so for this reason, it is termed as 'autotransporter'. The T5SSs are mostly responsible to secrete virulence factors but they are also found to participate in other processes like cell-to-cell adhesion and biofilm formation [16]. In its similarity to T2SS, the T5SS also needs the SecYEG translocon to be able to transfer an unfolded autotransporter polypeptide through the IM to the periplasm. The autotransporter consists of a secreted domain, which is called as 'passenger' domain, which is either semi- 
unfolded or fully unfolded in the periplasm, and a transmembrane domain (for the OM), which is also called the 'translocator' or ' $\beta$-domain' [17]. The translocator domain inserts into the $\mathrm{OM}$ as a $\beta$-barrel, which allows the secretion of the passenger domain through the pore of the $\beta$-barrel 9 [16]. Like other OM transport systems, this process is unique as there is no requirement of an ATP gradient or a proton gradient, as the energy required for transport is attained from the folding of the passenger domain at the pore exit [18]. The T5SS are further classified into five subclasses, denoted a-e [16].

\section{Type VI Secretion System (T6SS)}

The T6SS is the most recent characterized secretion system that appears to comprise injectisome which is a phage-tail-spike-like structure which plays a role of injecting proteins directly into the cytoplasm of the host cells [10], analogous to the structure of T3SS and T4SS. The T6SS machinery comprises mainly of two complexes: a membrane complex, which constitutes IM proteins that are homologous to components of the T4SS [10], and a tail complex that contains parts that are related to contractile bacteriophage tails: a tail sheath, an inner tube and a baseplate [19] The part of T6SS machinery, tail complex is associated to the cell envelope by the membrane complex. The tail sheath is a long tubular perpendicular structure to the membrane, which extends down into the bacterial cell cytoplasm [19]. Proper function and structure of the T6SS machinery are still poorly understood. 


\section{Type VII Secretion System (T7SS)}

This is a unique secretion system in itself, as it is found in gram-positive bacteria (have only single membrane) mycobacteria that have a cell wall, which is heavily modified by lipids, called mycomembrane. As a result, these species encode for specialized secretion system known as T7SS. So far, seven conserved genes are considered to be the core components of the secretion machinery of which two (EspG and EccA) are present in mycobacterial cytosol while others (EccB-EccE, and MycP) are present in the cell envelope [20]. It was shown that two residues within the C-terminal tail of mycobacterium substrates act as the recognition signal for the secretion [20]. Still studies are going on to give the more detailed structure and function of this system.

\section{Type VIII Secretion System (T8SS)}

T8SS also known as an extracellular nucleation-precipitation (ENP) pathway in gram-negative bacteria is responsible for the secretion and assembly of prepilins for fimbriae biogenesis, the prototypical curli [6]. This secretion system is different from others in a way that fibers growth occurs extracellularly [8]. The curli (Thin Aggregative Fimbriae (Tafi)) are the only fimbriae, for which assembly is dependent on T8SS [8]. They belong to the class of functional amyloids, participates in biofilm formation and interacting with the host immune system [21]. 


\section{Introduction to new secretion system in Porphyromonas gingivalis}

P. gingivalis, a bacterium which belongs to the Bacteroidetes phylum is considered to be one of the major periodontal pathogen [22]. The virulence of this bacterium is dependent on the wide variety of factors, which includes lipopolysaccharides, fimbriae, proteinases, hemagglutinins and hemolysins [22]. Among these virulence factors, secreted proteinases play a major role in the pathogenicity of P. gingivalis by directly degrading host tissue, activating host proenzymes, or neutralizing host immune system and also essential for acquisition of nutrients and hem (a vital growth factor and a source of black pigmentation of colonies on agar blood plate). Specific to the pathogenic potential of the bacterium, is a family of cysteine proteases called gingipains (RgpA, RgpB, and Kgp), which are found to be actively expressed and translocated across both the inner and outer membrane either to bind to the bacterial surface or secreted into the extra cellular milieu [23]. These gingipains have a typical cleavable signal peptide, a propeptide, a catalytic domain and C-terminal hemagglutination/adhesion domains (adhesion domains absent in RgpB). P. gingivalis lacks specific genes which are required for T2SS and T4SS and structurally, gingipain polypeptides lack the framework required for T1SS, T3SS, and T5SS. The absence of important components of known secretion systems (described above) in P. gingivalis, suggested there should be some other machinery that should be involved in the gingipain secretion. Gingipains are synthesized with a typical N-terminal signal peptide targeting them to the Sec machinery, which exports the protein across the IM and then they are translocated through the OM via a novel system composed of several OM, periplasmic, and IM proteins referred to as "Por Secretion System (PorSS)", or "PerioGate", or going 
with the conventional naming, Type IX Secretion System (T9SS) [24-26]. It was found that the machinery of this system is made of many proteins and knockout of any of these proteins, leads to the absence of gingipain activity and non-pigmented mutant phenotypes in which gingipains are found to accumulate in the periplasm, thus shutting the transport mechanism $[26,27]$.

\section{Type IX Secretion System (T9SS)}

Most of the secretion systems consist of many proteins that form a complex in the cell envelope and aid in the process of secretion across the outer membrane. Sato, et al [26] carried out experiments to identify the genes that might play a role in the secretion of the gingipains from the periplasm across the outer membrane, provided gingipains are synthesized with a typical N-terminal signal peptide targeting them to the Sec Secretion system that translocates gingipains from the cytoplasm to the periplasmic space. PorT, through genetic and biochemical analysis, was found to be important for gingipain secretion and may have a role in the interaction with other proteins to form the translocation machinery [28]. In addition to $\operatorname{por} T$, another 55 genes were identified which were present in $P$. gingivalis, and might have role in the secretion of gingipains $[26,28]$. It was interesting to find that these genes were also present in various other members of the Bacteroidetes phylum, including gliding bacteria such as Cytophaga hutchinsonii and Flavobacterium johnsoniae, and at the same time, they were not found in some members of the Bacteroidetes such as Bacteroides theaiotaomicron and B. fragilis [29]. In order to check the role of these genes in a secretion system, deletion mutants were generated for 46 of these genes in $P$. gingivalis and then these mutants were checked for the gingipains 
activity. Ten mutants with deletion of any of genes including $\operatorname{porK}$, porL, porM, porN, por $P$, por $Q$, porT, $\operatorname{por} U$, por $V$, and $\operatorname{por} W$ genes, resulted in the decreased activity of the gingipains (Rgp and Kgp) in cells and culture supernatants [26]. Deletion of the sov gene has shown Sov plays a role in the gingipains secretion [30]. The mutants also showed that the less active gingipains were accumulated in the periplasm, concluding that the T9SS machinery is composed of proteins encoded by these genes, which are responsible for the gingipains secretion across the outer membrane. PorK, PorN, and PorP were detected in the outer membrane fraction, whereas PorL and PorM were detected in the inner membrane fraction (Figure 3) [26]. This novel secretion system was referred to as PorSS (Por Secretion System) and now referred to as T9SS (Type IX Secretion System) $[26,28-30]$

PorX and PorY were found to be similar to response regulator proteins and histidine sensor kinases (Figure 3) of two-component signal transduction systems [26]. They might play a role in the regulation of expression of genes of the transport system. Many of the genes found to play a role in gingipains secretion were down regulated in the por $X$ and $\operatorname{por} Y$ deletion mutants [26, 31]. Also, they were down regulated in a mutant deficient in putative extracytoplasmic function (ECF) sigma factor, SigP, as in case with porX mutant. Mutation analysis indicates that SigP binds to the promoter region of T9SS component-encoding genes [31]. Direct interaction of SigP and PorX suggested that PorXY two-component system regulates protein secretion mediated by T9SS via the SigP ECF sigma factor [31]. 


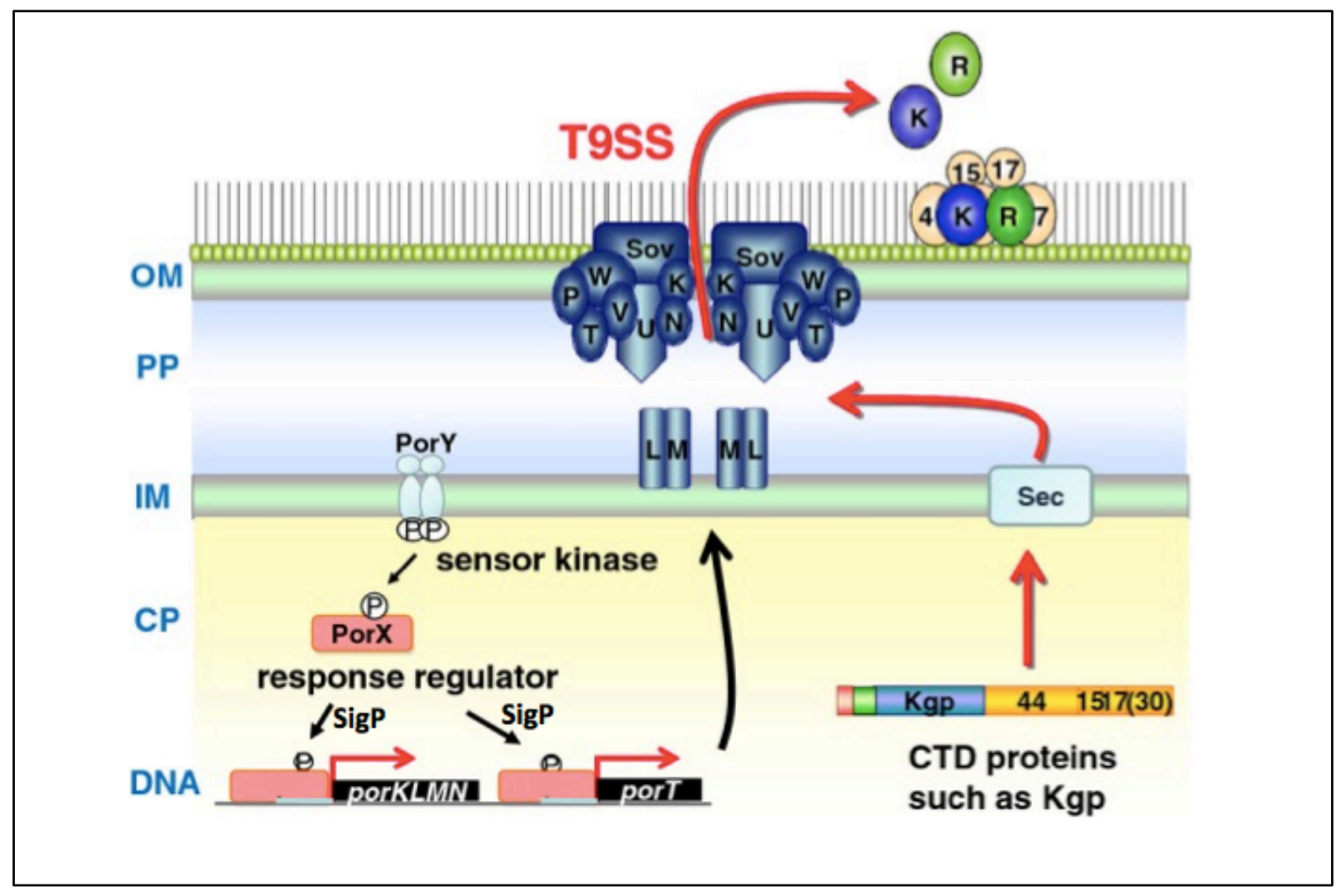

Figure 3. Model of the T9SS (Type IX Secretion System) of $\boldsymbol{P}$. gingivalis.

T9SS comprises of more than 10 proteins, which includes PorK, PorL, PorM, PorN, PorP, PorQ, PorT, PorU, PorV, PorW and Sov. Some of these proteins were expressed using the two-component system PorXY. PorX and PorY are a response regulator and a sensor kinase, respectively. CTD proteins, such as Kgp (K) and Rgp (R), are translocated across the IM via Sec machinery and subsequently secreted across the OM through the T9SS. CTD, C-terminal domains; CP, cytoplasm; IM, inner membrane; OM, outer membrane; PP, periplasm; SigP, extracytoplasmic function sigma factor. Modified and Adapted from Nakayama [29].

Studies show that secretion of RgpB (member of gingipain family) from the periplasm across the outer membrane is dependent on the conserved C-Terminal Domain (CTD) [32]. Lack of the CTD leads to the accumulation of gingipains in the periplasm itself and it prevents gingipains from attaching to the outer membrane, which suggests that CTD plays an essential role in the secretion of proteins [33]. It is the CTD, which is present in the cargo proteins of $P$. gingivalis and act as the recognition signal to the T9SS 
machinery to be secreted outside the cell and PorU (an essential component of T9SS, acts as a sorting protease) is responsible for cleaving off the CTDs from cargo proteins as they pass through the outer membrane [34]. More than 30 proteins, including gingipains in P. gingivalis were found to possess CTDs (Figure 4, CTD alignment) based on the sequences of gingipains (known to have CTD) and also various proteins out of these are found to be post-translationally modified during the secretion via T9SS and forming an electron dense layer along with gingipains on the cell surface $[35,36]$.

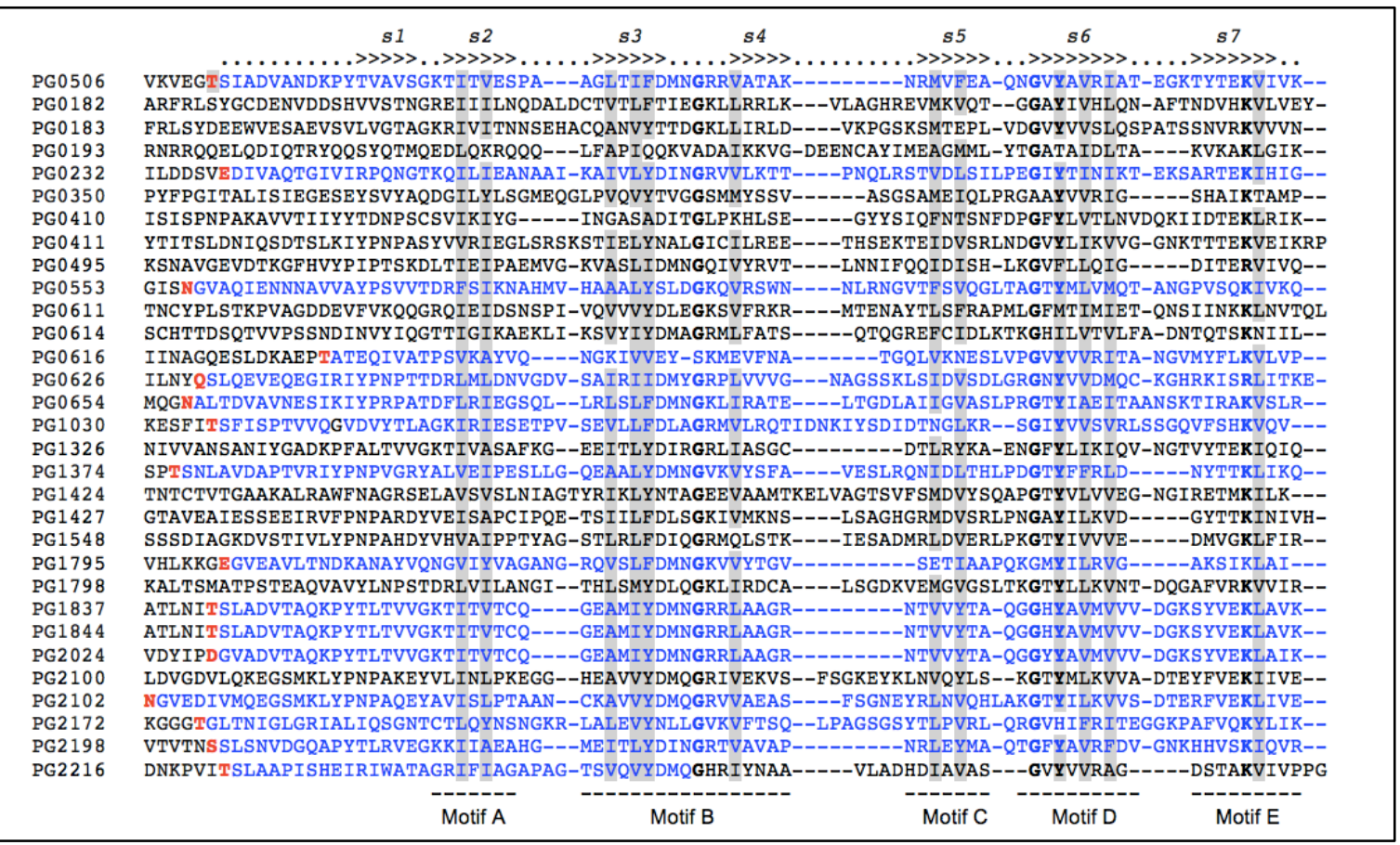

Figure 4. The structure-based alignment of the CTD of proteins secreted by $\boldsymbol{P}$. gingivalis via T9SS. Conserved hydrophobic residues in $\beta$-strands are highlighted. CTDs predicted from MS analysis of culture media are typed in blue with residues after which proteolysis occurred marked in a bold red font. Adapted from Veith, Nor Muhammad [35]. 
T9SS is not only found with $P$. gingivalis but have been extended to other members of the Bacteroidetes phylum, which is associated with gliding motility [26, 37]. A comparative study was done with 37 bacterial genomes that revealed T9SS genes belonging to the phylum Bacteroidetes [37]. The mutant analysis found functional T9SSs in three other bacterial species, Cytophaga hutchinsonii, Tannerella forsythhia and Flavobacterium jonsoniae, associated with gliding motility adhesins and also cell surface associated enzymes needed for digestion of crystal line cellulose and chitin [29, 37, 38].

\section{Posttranslational modification of T9SS cargo proteins during secretion}

As described earlier, the CTD are cleaved off from T9SS cargo proteins during the translocation across the outer membrane and they remain associated with the cell surface $[26,34]$. The anchorage of secreted proteins to the $\mathrm{OM}$ is possible due to the moiety of anionic-lipopolysaccharide (A-LPS) covalently attached to the C-termini of secreted proteins. Apparently the cleavage of the CTD by sortase and attachment of A-LPS occurs concurrently as shown schematically in figure 5 for RgpB (right pathway) [39]. Of note, $P$. gingivalis is unique since it has two types of lipopolysaccharides (LPS), A-LPS and O-LPS and the basic difference between both of them is, the repeating polysaccharide [39]. In the case of RgpB and PPAD it was shown that the covalent attachment of A-LPS to the protein after CTD cleavage, depends on the length of the linker sequence between the CTD and the preceding immunoglobulin-superfamily domain (IgSF) since insertion of the hexahistidine motif in front of the CTD caused secretion into growth medium of the soluble, non-glycosylated forms of these proteins bearing 6xHis at the C-termini (as shown in figure 5) [40]. 


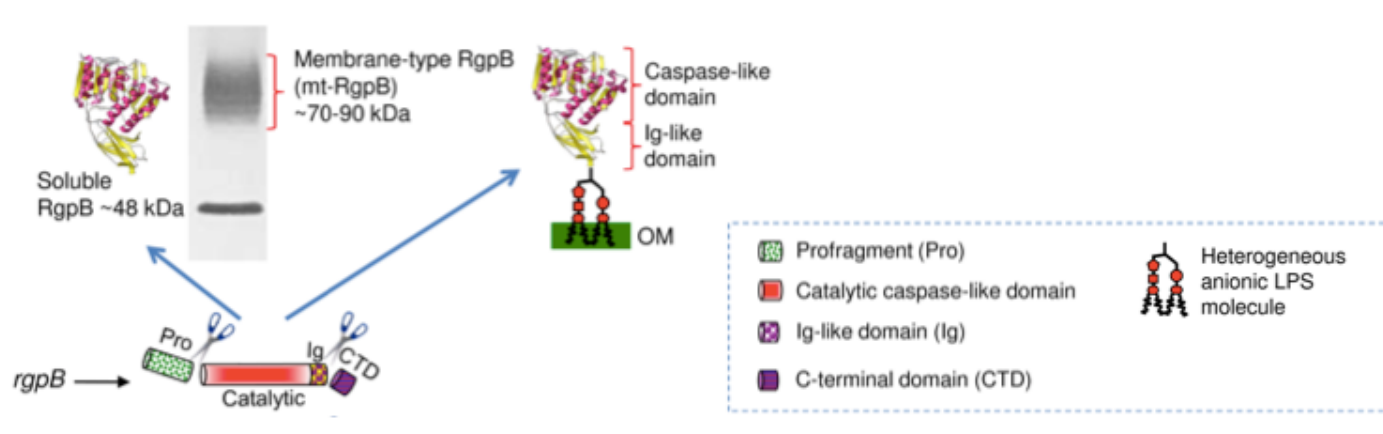

Figure 5. Schematic diagram of RgpB produced by $\boldsymbol{P}$. gingivalis. RgpB is translocated into the periplasm as polyproteins composed of a pro-fragment, a protease domain and a C-terminal domain (CTD). Proteolytic processing of RgpB polyprotein releases catalytic domain, which is noncovalently associated with absence of profragment and CTD. In addition to proteolytic processing, $\operatorname{RgpB}$ is post-translationally modified by attachment of a heterologous moiety of A-LPS and remain associated with OM on the bacterial surface. Western blot analysis (Shown at top) of the whole culture of $P$. gingivalis using anti-RgpB monoclonal antibodies illustrates the difference in molecular mass between soluble and membrane attached RgpB. The structure of the Rgp protease is known. It is composed of the caspase-like catalytic domain and the immunoglobin like (Ig-like) domain. Adapted from Oral Microbiology and Immunology. 2nd ed,. Hajishengallis G.N., Jenkinson H.F., and Lamont R.J. 2014, Washington, DC: American Society for Microbiology. 


\title{
CHAPTER 2
}

\section{RESEARCH HYPOTHESIS AND SPECIFIC AIMS}

\section{Research Hypothesis}

We hypothesize that insertion of a hexahistidine affinity tag upstream of the C-terminal outer membrane translocation signal (CTD) in C25 peptidase (PG_RS01820), Carboxypeptidase /CPG70 (PG_RS01060) and Periodontain /PrtT related (PG_RS06260), T9SS cargo proteins of $P$. gingivalis, will result in their secretion in soluble, mature forms, bearing the affinity tag thus facilitating their purification by affinity chromatography.

\section{$\underline{\text { Specific Aims }}$}

\begin{abstract}
Aim 1: To insert 6xHis encoding motive in front of the CTD coding sequence in selected T9SS substrates including: C25 peptidase (PG_RS01820), Carboxypeptidase /CPG70 (PG_RS01060) and Periodontain /PrtT related (PG_RS06260) (Figure 6).
\end{abstract}

Aim 2: To purify and produce proteases for further analysis. 


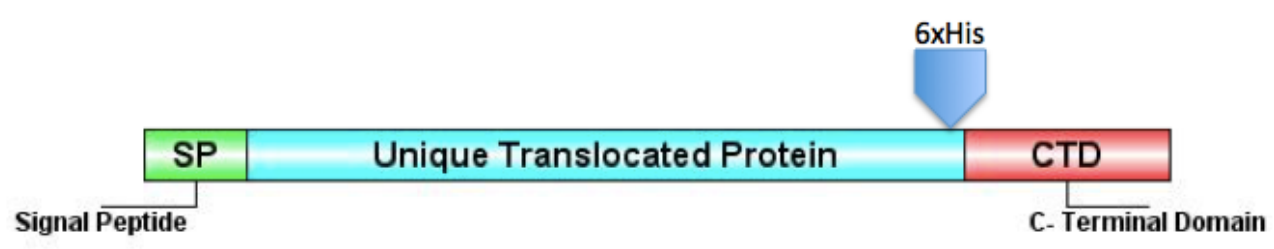

Domain Structure of T9SS Cargo Proteins

Figure 6. Schematic view of the domain structure of T9SS cargo proteins. This figure shows the indicated insertion site of the hexahistidine motif just in the front of a determined or predicted cleavage site of CTD by PorU. 


\section{CHAPTER 3}

\section{MATERIALS AND METHODS}

\subsection{Bacterial strains and general growth conditions}

Porphyromonas gingivalis wild-type strain W83 and mutant derivatives (Table 1) were grown in enriched tryptic soy broth medium (eTSB: $30 \mathrm{~g}$ trypticase soy broth, 5 g yeast extract, per liter, $\mathrm{pH} 7.5$ and supplemented with $0.5 \mathrm{~g}$ L-cysteine, $5 \mathrm{mg}$ hemin and $2 \mathrm{mg}$ menadione) or on blood eTSB agar (eTSB medium +15 g agar per liter and supplemented with $4 \%$ defibrinated sheep's blood) at $37^{\circ} \mathrm{C}$ in an anaerobic chamber in an atmosphere of $90 \% \mathrm{~N}_{2}, 5 \% \mathrm{CO}_{2}$ and $5 \% \mathrm{H}_{2}$. Escherichia coli strain NEB $^{\circledR}$ 5-alpha, New England BioLabs (DH5 $\alpha$ derivative) and OneShot ${ }^{\circledR}$ Top10 (Invitrogen) were used for all plasmid construction work and was grown in Luria-Bertani medium and agar. For antibiotic selection in E. coli, ampicillin was used at $100 \mu \mathrm{g} / \mathrm{ml}$. For $P$. gingivalis growth selection on solid media, erythromycin and ampicillin were used at concentration of $5 \mu \mathrm{g} / \mathrm{ml}$ and $6 \mu \mathrm{g} / \mathrm{ml}$, respectively. 
Table 1. Bacterial strains used in the study.

\begin{tabular}{|c|c|c|}
\hline \multicolumn{3}{|c|}{$P$. gingivalis strains and mutants used in this study } \\
\hline Strain & Description & Source/Reference \\
\hline W83 & Wild-type & Reference [41] \\
\hline AG002 & $\begin{array}{l}\text { Insertion of } 6 \times \mathrm{xHis} \text { at site } \mathrm{G} 760 \text { in } \\
\text { Periodontain }\left(\mathrm{PG} \_\mathrm{RS} 06260\right)\end{array}$ & This study \\
\hline AG003 & $\begin{array}{l}\text { Insertion of } 6 \times \mathrm{xHis} \text { at site } \mathrm{T} 761 \text { in } \\
\text { Periodontain }\left(\mathrm{PG} \_\mathrm{RS} 06260\right)\end{array}$ & This study \\
\hline AG004 & $\begin{array}{l}\text { Insertion of } 6 x H i s \text { at site K1191 in } \\
\text { C25 peptidase (PG_RS01820) }\end{array}$ & This study \\
\hline AG005 & $\begin{array}{l}\text { Insertion of } 6 x H i s \text { at site K1198 in } \\
\text { C25 peptidase (PG_RS01820) }\end{array}$ & This study \\
\hline AG006 & $\begin{array}{l}\text { Insertion of 6xHis at site D738 in } \\
\text { CPG70 (PG_RS01060) }\end{array}$ & This study \\
\hline \multicolumn{3}{|c|}{ E. coli strains used in this study } \\
\hline NEB 5-alpha & $\begin{array}{l}\text { DH5-alpha derivative; Genotype: } \\
\text { fhuA2 } \triangle(\text { argF-lacZ)U169 phoA } \\
\text { glnV44 } \$ 80 \Delta(\text { lacZ)M15 gyrA96 } \\
\text { recAl relAl endA1 thi-1 hsdR17 }\end{array}$ & New England BioLabs \\
\hline One Shot TOP10 & $\begin{array}{l}\text { Genotype: } F \text { - mcrA } \triangle(\text { mrr-hsdRMS- } \\
\text { mcrBC) } \text { \$80lacZAM15 } 4 \text { lacX74 } \\
\text { recAl araD139 } \Delta(\text { araleu) } 7697 \\
\text { galU galK rpsL (StrR) endA1 nupG }\end{array}$ & Invitrogen \\
\hline
\end{tabular}

\subsection{Polymerase Chain Reaction (PCR)}

Standard polymerase chain reactions were carried out with the use of Phusion High-

Fidelity DNA Polymerase (Thermo Scientific) according to 3-step protocol provided in the manufacturer manual. Chromosomal DNAs of $P$. gingivalis W83 strain or its derivatives were used as a template. Oligonucleotides used in reactions are listed in Table 3 and 6. 
The PCR reaction was as follows:

5X HF Buffer $\quad 0 \mu l$

DNA (W83) Template (50ng) $\quad \mathrm{x} \mu \mathrm{l}$

$10 \mathrm{mM}$ dNTPs $\quad 1 \mu \mathrm{l}$

Primer F* $(100 \mu \mathrm{M}) \quad 0.5 \mu \mathrm{l}$

Primer R* $(100 \mu \mathrm{M}) \quad 0.5 \mu \mathrm{l}$

Phusion Polymerase $(2 \mathrm{u} / \mu \mathrm{l}) \quad 0.5 \mu \mathrm{l}$

Sterile Water to a final volume of $\quad 50 \mu \mathrm{l}$

$* \mathrm{~F}=$ Forward $\mathrm{R}=$ Reverse

Table 2. The PCR program used to amplify different fragments of $P$. gingivalis W83 chromosomal DNA.

\begin{tabular}{llll}
\hline Step & Time & Temperature & Cycles \\
\hline 1.Initial & 2 minutes & $98^{\circ} \mathrm{C}$ & $\mathbf{1 X}$ \\
2. Denaturation & $5-10$ seconds & $98^{\circ} \mathrm{C}$ & $\mathbf{3 4 X}$ \\
3. Annealing & $10-30$ seconds & $65-72^{\circ} \mathrm{C}$ & $\mathbf{3 4 X}$ \\
4. Extension & $15-30 \mathrm{~s} / \mathrm{kb}$ & $72^{\circ} \mathrm{C}$ & $\mathbf{3 4 X}$ \\
5. Final Extension & 10 minutes & $72^{\circ} \mathrm{C}$ & $\mathbf{1 X}$ \\
\hline 6. Storage & Hold & $\mathbf{4}^{\circ} \mathbf{C}$ & $\infty$ \\
\hline
\end{tabular}

*Go to step 2.34 times more

Amplified fragments were resolved through agarose gel electrophoresis (see 3.4), appropriate bands were cut out and DNA was extracted with a use of GeneJET Gel Extraction and DNA Cleanup Micro Kit (see 3.5). 
Table 3. Primers used for the amplification of gene of interest.

\begin{tabular}{|l|l|l|}
\hline \multicolumn{3}{|l|}{ Primers and template used for amplification of gene of interest } \\
\hline Name & Sequence* 5'-3' & Target \\
\hline PG_RS_06260_EcoRI & $\begin{array}{l}\text { TTGTCGCAGATCTGAATTCTTA } \\
\text { TG (Fwd) }\end{array}$ & $\begin{array}{l}\text { PG_RS06260 } \\
\text { (UP fragment) }\end{array}$ \\
\hline PG_RS_06260_SmaI & $\begin{array}{l}\text { ACGTGCTTCCCGGGTCTATC } \\
\text { (Rev) }\end{array}$ & $\begin{array}{l}\text { PG_RS06260 } \\
\text { (UP fragment) }\end{array}$ \\
\hline PG_RS_06255_XbaI & $\begin{array}{l}\text { GATTCTAGAGGGAAGCACGTA } \\
\text { ATAAGG (Fwd) }\end{array}$ & $\begin{array}{l}\text { PG_RS06260 } \\
\text { (DOWN fragment) }\end{array}$ \\
\hline PG_RS_06255_HindIIII & $\begin{array}{l}\text { CCAAAGCTTCCTCCAACCCGAT } \\
\text { AAC (Rev) }\end{array}$ & $\begin{array}{l}\text { PG_RS06260 } \\
\text { (DOWN fragment) }\end{array}$ \\
\hline PG_RS01820_SacI & $\begin{array}{l}\text { GGCGAGCTCGATTTGTTTGATC } \\
\text { CGAATC (Fwd) }\end{array}$ & $\begin{array}{l}\text { PG_RS01820 } \\
\text { (UP fragment) }\end{array}$ \\
\hline PG_RS01820_SmaI & $\begin{array}{l}\text { CTCCCCGGGAGTCGGATTCGTG } \\
\text { ATCGC (Rev) }\end{array}$ & $\begin{array}{l}\text { PG_RS01820 } \\
\text { (UP fragment) }\end{array}$ \\
\hline PG_RS01825_XbaI & $\begin{array}{l}\text { CACTCTAGAGACTGCTCAAGAG } \\
\text { ATCTC (Fwd) }\end{array}$ & $\begin{array}{l}\text { PG_RS01820 } \\
\text { (DOWN fragment) }\end{array}$ \\
\hline PG_RS01825_HindIII & $\begin{array}{l}\text { GTGAAGCTTGCTAAATCCATCT } \\
\text { CCATC (Rev) }\end{array}$ & $\begin{array}{l}\text { PG_RS01820 } \\
\text { (DOWN fragment) }\end{array}$ \\
\hline
\end{tabular}

* Restriction enzyme is marked with underline; Fwd = Forward Rev = Reverse

\subsection{Digestion of DNA with restriction enzymes}

DNA (plasmid or PCR product) at concentrations up to $1 \mu \mathrm{g}$ in total volume of $20 \mu \mathrm{l}$ was digested with the appropriate restriction enzyme(s), according to manufacturer's manual (FastDigest; Thermo Scientific). The reaction was performed at $37^{\circ} \mathrm{C}$ for 15 minutes. To prevent self-ligation of plasmid vectors in following ligation reaction the terminal 5'-phosphate groups were removed with a use of FastAP Thermosensitive Alkaline Phosphatase (1 U/ $\mu \mathrm{L}$; Thermo Scientific). Digested DNA was resolved through agarose gel electrophoresis (see 3.4), appropriate bands were cut out and DNA was extracted with a use of GeneJET Gel Extraction and DNA Cleanup Micro Kit (see 3.5). In case DNA 
was used right after digestion, the FastDigest enzymes were heat-inactivated according to the manufacturer's manual.

\subsection{Agarose gel electrophoresis}

DNA of digested plasmids or PCR products was separated through agarose gel electrophoresis.

Preparing the gel

1. $0.8 \%$ agarose gel was made by mixing 0.8 grams agarose with $98 \mathrm{ml}$ distilled water and $2 \mathrm{ml} 50 \mathrm{X}$ TAE buffer.

2. The mixture was heated in a microwave oven until all agarose had melted and the solution had started to boil.

3. The gel solution was then left to cool (to approximately $65^{\circ} \mathrm{C}$ ).

4. Midori Green Advance DNA Stain $(4 \mu 1-6 \mu l)$ was added after the mixture had cooled, and gently mixed into the agar.

5. The gel was poured slowly into a gel rack, the comb was set at one side of the gel, and any bubbles in the solution removed. The gel was allowed to set (15 to 20 minutes).

6. After 20 minutes, when the gel had solidified, the comb was removed, and the gel, together with the rack, was soaked into a chamber with $1 \mathrm{X}$ TAE gel running buffer. The gel was placed with the wells facing the electrode that provide the negative current (cathode). 


\section{Loading and running the gel}

Loading buffers were added to the DNA samples in order to visualize and sediment it in the gel wells.

1. A DNA ladder (Thermo Scientific GeneRuler 1kb DNA Ladder shown in figure 7), a mixture of DNA fragments of known size, was loaded along with analyzed samples. This was used to determine the absolute size of the separated DNA strand by comparing their migration with that of the ladder (see Figure 7).

2. The samples were loaded into the wells and the lid of the electrophoresis chamber was closed and the current was applied. The gel was run at 90-120 volts (usually 50 minutes).

3. The Midori Green Advance DNA stained gel was visualized under UV light and photographed. Eventually the required DNA band was cut out and a GeneJET Gel Extraction was used to purify (see 3.5 )

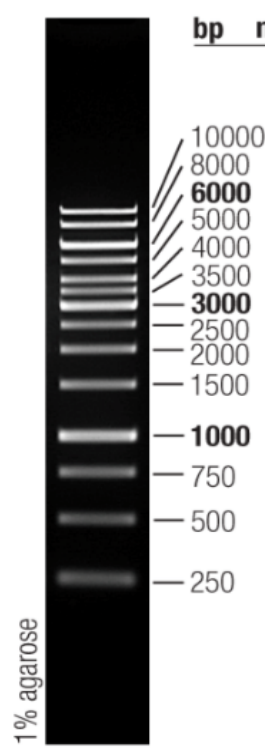

Figure 7. One kb DNA Ladder (Thermo Scientific). 


\subsection{DNA purification}

DNA fragments obtained after enzymatic reactions (digestions or PCR) were purified either directly after reaction or were resolved in agarose gel and then bands were cut and purified using GeneJET Gel Extraction and DNA Cleanup Micro Kit (Thermo Scientific) as described in the protocol provided by the manufacturer.

\subsection{DNA ligation}

DNA fragments were ligated with a use of T4 DNA ligase (Thermo Scientific) according to the manufacturer's manual. Usually, $0.2-0.3 \mu \mathrm{g}$ of vector DNA was mixed with an insert DNA in 1:3 molar ratios. The ligation mixture was incubated overnight at $22^{\circ} \mathrm{C}$ followed by ligase inactivation at $65^{\circ} \mathrm{C}$ for 10 min prior transformation. 
Table 4. Plasmids used in the study.

\begin{tabular}{|c|c|c|}
\hline \multicolumn{3}{|c|}{ Plasmids used in this study } \\
\hline Plasmid & Description & Source/Reference \\
\hline pCpgCeB & $\begin{array}{l}\text { Master plasmid of PG_RS01060 with } \\
\text { erythromycin resistant gene. }\end{array}$ & $\begin{array}{l}\text { Ky-Anh Nguyen, Ph.D. } \\
\text { University of Sydney, } \\
\text { Australia }\end{array}$ \\
\hline pAL7 & $\begin{array}{l}\text { pUC19 derivative with cepA cassette } \\
\text { (ampicillin resistance). }\end{array}$ & $\begin{array}{l}\text { Oral Immunology and } \\
\text { Infectious Diseases, ULSD }\end{array}$ \\
\hline pAG2 & $\begin{array}{l}\text { pAL7 with PG_RS06260 (UP fragment) } \\
\text { inserted at EcoRI and Smal site. }\end{array}$ & This study \\
\hline pAG3 & $\begin{array}{l}\text { pAG2 with PG_RS06260 (DOWN } \\
\text { fragment) inserted at Xbal and HindIII site. }\end{array}$ & This study \\
\hline pAG4 & $\begin{array}{l}\text { pAL7 with PG_RS01820 (UP fragment) } \\
\text { inserted at SacI and SmaI site. }\end{array}$ & This study \\
\hline pAG5 & $\begin{array}{l}\text { pAG4 with PG_RS01820 (DOWN } \\
\text { fragment) inserted at XbaI and HindIII site. }\end{array}$ & This study \\
\hline pAG8 & pAG3 with 6His insertion at G760 & This study \\
\hline pAG9 & pAG3 with 6 His insertion at T761 & This study \\
\hline pAG10 & pAG5 with 6 His insertion at K1191 & This study \\
\hline pAG11 & pAG5 with 6 His insertion at K1198 & This study \\
\hline pAG12 & pCpgCeB with 6 His insertion at D738 & This study \\
\hline
\end{tabular}

\subsection{Transformation of Plasmid into competent E. coli NEB $\alpha$ /One Shot TOP10 cells}

Transformation into competent cells was carried out according to the manufacturer's protocol and after that a few (usually 4) antibiotic-resistant colonies were picked and transferred to LB medium (LB agar plate as well as liquid). Plates were kept for incubation at $37^{\circ} \mathrm{C}$ and liquid media was incubated at $37^{\circ} \mathrm{C}$ with vigorous shaking at 225 rpm overnight.

The plates were stored at $4{ }^{\circ} \mathrm{C}$ and plasmid was extracted from the liquid culture using the GeneJET Plasmid Miniprep Kit. 


\subsection{Extraction of plasmids from bacterial cells}

GeneJET Plasmid Miniprep Kit was used for efficient purification of plasmids. Steps were followed according to the manufacturer's protocol. All newly constructed plasmids were firstly checked through restriction analysis and the proper construction was further analyzed by sequencing.

\subsection{DNA concentration measurements}

Nanodrop 2000 spectrophotometer from Thermo Scientific was used to measure the DNA concentration.

\subsection{DNA Sequencing}

DNA samples (plasmids or PCR products) were sent for sequencing to The Center for Genetics and Molecular Medicine Sequencing Service, University of Louisville.

\section{Sample Preparation}

$0.4 \mu \mathrm{g}$ of clean plasmid DNA or PCR products (6ng/100 bases) in total volume of $10.4 \mu \mathrm{l}$ were mixed with $1.6 \mu \mathrm{l}$ of appropriate primer $(20 \mu \mathrm{M}$ stock solution). 
Table 5. Primers used in the study for sequencing.

\begin{tabular}{|l|l|l|}
\hline \multicolumn{3}{|l|}{ Primers used for sequencing in this study } \\
\hline Primer Name & Recognition Site & Recognition Sequence \\
\hline M13pUCf & pUC19-MCS* & CCCAGTCACGACGTTGTAAAACG \\
\hline M13pUCr & pUC19- MCS & AGCGGATAACAATTTCACAGG \\
\hline CepA_seq_fwd1 & pAL7-cep gene & AGATTCCGAAGCAGATAAC \\
\hline CepA_seq_rev1 & pAL7-cep gene & ATCTATCTGTTGCGTTACG \\
\hline CepA_seq_rev2 & pAL7-cep gene & CTCCCTGTGGGTATGTTTC \\
\hline CepA_seq_rev3 & pAL7-cep gene & CTTCATCCTCCAATGTTTC \\
\hline PG_RS06260_seq & PG_RS06260 & TACGACAGACCCGAACAATG \\
\hline PG_RS06260_seq_Nde & PG_RS06260 & GAACATATGATAAGATCTCG \\
\hline PG_RS06260_seq_BamHI & PG_RS06260 & ATAGGATCCATCAGGTATAG \\
\hline PG_RS01820_seq_up & PG_RS01820 & CTTCCATTACAACAGCTTGCAGGG \\
\hline PG_RS01825_seq & PG_RS01820 & CCCGGAACATAAGAAGCCGAC \\
\hline PG_RS01060_Seq1Rev & PG_RS01060 & TTCGTCTTCACTGGTAGC \\
\hline PG_RS01060_Seq2 & PG_RS01060 & GGCCAGACGGTATCTTTCC \\
\hline PG_RS01060_Seq3 & PG_RS01060 & CAATGGACGGGTCGTACTC \\
\hline PG_RS01055_Seq1 & PG_RS01060 & CGACACTCATGATCGTAGC \\
\hline PG_RS01060_SEQ_rev & PG_RS01060 & GTAGATTCCTTCGGGCAGGATGG \\
\hline
\end{tabular}

*MCS- Multi-Cloning Sites

\subsection{Insertion and site-directed mutagenesis of the master plasmid construct.}

Phusion Site-Directed Mutagenesis Kit (Thermo Scientific) was used to create insertions of the oligonucleotide motif encoding hexahistidines into designated sites in the genes of interest in the master plasmids. Briefly, for each mutagenesis reaction, sets of two phosphorylated primers were designed (Table 6), adjacent to each other but have opposite orientation. One primer contained 5' extension encoding for the hexahistidine peptide. After specific DNA amplification T4 DNA Ligase was used for the circularization of a mutated plasmid and then transformation was carried out as described in section 3.7. 
Obtaining of mutated plasmids (with insertions of the hexahistidine encoding sequence) were confirmed through sequencing (see 3.10)

Table 6. Phosphorylated primers used to insert $6 \mathrm{His}$ tags in the plasmids.

\begin{tabular}{|c|c|c|c|}
\hline $\begin{array}{l}\text { Protein / Gene } \\
\text { (Master plasmid) }\end{array}$ & $\begin{array}{l}\text { Insertion } \\
\text { Site }\end{array}$ & Primers & Primer Sequence \\
\hline \multirow{4}{*}{$\begin{array}{l}\text { Periodontain } \\
\text { PG_RS06260 } \\
\text { (pAG3) }\end{array}$} & \multirow[t]{2}{*}{$\mathbf{G}^{760}$} & PG_06260_G760_Rev1 & $\begin{array}{l}\text { GTGATGGTGATGGTGATGACCA } \\
\text { TTGACGATCTTCAC }\end{array}$ \\
\hline & & PG_06260_G760_Fwd2 & $\begin{array}{l}\text { ACAGCGGTAGAAGCAATAGAA } \\
\text { TCG }\end{array}$ \\
\hline & \multirow[t]{2}{*}{$\mathbf{T}^{761}$} & PG_06260_T761_Rev1 & $\begin{array}{l}\text { GTGATGGTGATGGTGATGTGTA } \\
\text { CCATTGACGATCTTC }\end{array}$ \\
\hline & & PG_06260_T761_Fwd2 & $\begin{array}{l}\text { GCGGTAGAAGCAATAGAATCG } \\
\text { TCAG }\end{array}$ \\
\hline \multirow{4}{*}{$\begin{array}{l}\text { C25 protease } \\
\text { PG_RS01820 } \\
\text { (pAG5) }\end{array}$} & \multirow[t]{2}{*}{$\mathbf{K}^{1191}$} & M1_Fwd & $\begin{array}{l}\text { TCAAGCCTTGATAAATCCAAGA } \\
\text { TAATC }\end{array}$ \\
\hline & & 6xHis_M1_Rev & $\begin{array}{l}\text { ATGGTGATGGTGATGGTGTTTG } \\
\text { TTGCATTCTAATG }\end{array}$ \\
\hline & \multirow[t]{2}{*}{$\mathbf{K}^{1198}$} & 6xHis_M2_Fwd & $\begin{array}{l}\text { CACCATCACCATCACCATATAA } \\
\text { TCTCTATTTCGCCCAATC }\end{array}$ \\
\hline & & M2_Rev & $\begin{array}{l}\text { CTTGGATTTATCAAGGCTTGAT } \\
\text { TTG }\end{array}$ \\
\hline \multirow{2}{*}{$\begin{array}{c}\text { CPG70 } \\
\text { PG_RS01060 } \\
\text { (pCpgCeB) }\end{array}$} & \multirow[t]{2}{*}{$\mathbf{D}^{738}$} & PG_RS01060_i_D738_RevB & $\begin{array}{l}\text { GTGATGGTGATGGTGATGGTCA } \\
\text { TCGAGGATAACCTCAATG }\end{array}$ \\
\hline & & PG_RS01060_nt_D738_FwdC & $\begin{array}{l}\text { AGTGTCGAGGACATAGTGGCA } \\
\text { CAGAC }\end{array}$ \\
\hline
\end{tabular}

\subsection{Generation of isogenic mutants via homologous recombination.}

Insertions of DNA fragments encompassing modified genes of interest (bearing the 6xHis encoding motif) into the $P$. gingivalis genome were performed through homologous recombination. Suicide plasmids containing mutated genes of interest were introduced to P. gingivalis cells by the electroporation. Briefly, a 40-ml mid-log-phase culture of P. gingivalis was harvested by centrifugation at $6,000 \times g$ for $15 \mathrm{~min}$, washed three times 
in electroporation buffer $(10 \%$ glycerol [ $\mathrm{vol} / \mathrm{vol}], 1 \mathrm{mM} \mathrm{MgCl} 2)$, and re-suspended in 0.5 $\mathrm{ml}$ of the same buffer. All steps were carried out at $4^{\circ} \mathrm{C}$. Two hundred microliters of the cell suspension was transferred into a pre-chilled 0.2-cm-gap width electroporation cuvette along with $1 \mu \mathrm{g}$ of plasmid DNA. Electroporation was carried out at $2.5 \mathrm{kV}$ and $10 \mu \mathrm{F}$ capacitance using a micropulser electroporation apparatus (Bio-Rad Laboratories), resulting in time constants of approximately $4.5 \mathrm{msec}$. After electroporation, the cells were allowed to recover on ice for $2 \mathrm{~min}$ before the addition of $1 \mathrm{ml}$ of eTSB medium to the suspension. Cells were allowed to grow anaerobically at $37^{\circ} \mathrm{C}$ overnight before being plated onto antibiotic selective media. Resistant clones were further sub cultured on selective plates, and genomic integration by a double crossover event was confirmed by PCR. DNA sequencing of the pertinent region of the genome further verified mutants.

\subsection{Purification of His-tagged proteins from $P$. gingivalis culture media}

The growth media of $P$. gingivalis mutant strains expressing Periodontain-6xHis, C25 peptidase-6xHis and CPG70-6xHis were clarified by centrifugation at 8,000xg, 30 min at $4{ }^{\circ} \mathrm{C}$ to remove cells and large cellular debris. Proteins in cell-free media were precipitated with acetone (1.5 volume of acetone per 1 volume of medium) added slowly over 30 min to medium with temperature maintained below $0^{\circ} \mathrm{C}$ and with vigorous stirring. Precipitate was collected by centrifugation at $8,000 \mathrm{xg}, 30 \mathrm{~min}$, and $4^{\circ} \mathrm{C}$. The pellet was re-suspended in a binding buffer $(20 \mathrm{mM}$ sodium phosphate, $0.5 \mathrm{M} \mathrm{NaCl}, 10$ $\mathrm{mM}$ imidazole, $\mathrm{pH}$ 7.4), clarified by centrifugation and passed through a column a nickel- 
sepharose resin (GE Healthcare Life Sciences). Column was equilibrated with the binding buffer before loading a sample. After extensive washing with Binding buffer (20 mM sodium phosphate, $0.5 \mathrm{M} \mathrm{NaCl}, 20 \mathrm{mM}$ imidazole, $\mathrm{pH}$ 7.4), protein fraction bound to nickel-sepharose matrix was eluted with Elution buffer $(20 \mathrm{mM}$ sodium phosphate, $0.5 \mathrm{M}$ $\mathrm{NaCl}, 500 \mathrm{mM}$ imidazole, $\mathrm{pH}$ 7.4). Obtained elute was concentrated by ultrafiltration and samples from different steps of purification were resolved through SDS-PAGE method and further analyzed by Western-blot.

\subsection{SDS-PAGE}

To an appropriate amount of sample solution $(50 \mu \mathrm{l})$, in a $1.5-\mathrm{ml}$ microcentrifuge tube, TLCK (from $200 \mathrm{mM}$ stock) to a final concentration of $2 \mathrm{mM}$ was added. It was then incubated for 10 minutes at room temperature. Five $\mu l$ of $4 \times$ non-reducing sample buffer (NuPAGE LDS Sample Buffer) was added and samples heated in a $100^{\circ} \mathrm{C}$ thermoblock for $10 \mathrm{~min}$. Samples were briefly microcentrifuged to bring all fluid to the bottom of the tube. Then $5 \mu 1$ of a reducing reagent (10\% 2-mercaptoethanol with $90 \%$ of LDS Sample Buffer) was added and samples were heated at $100^{\circ} \mathrm{C}$ for another $10 \mathrm{~min}$. Samples were microcentrifuged briefly and then appropriate amount was loaded onto the gel. Gel was run for 60 minutes at 150 Volts. Gels were stained with SimplyBlue SafeStain (NOVEX) for $1 \mathrm{~h}$ and then distained and visualized under light. $10 \mu \mathrm{l}$ of standard (Precision Plus Protein Kaleidoscope) was used as the protein ladder (Figure 8). 


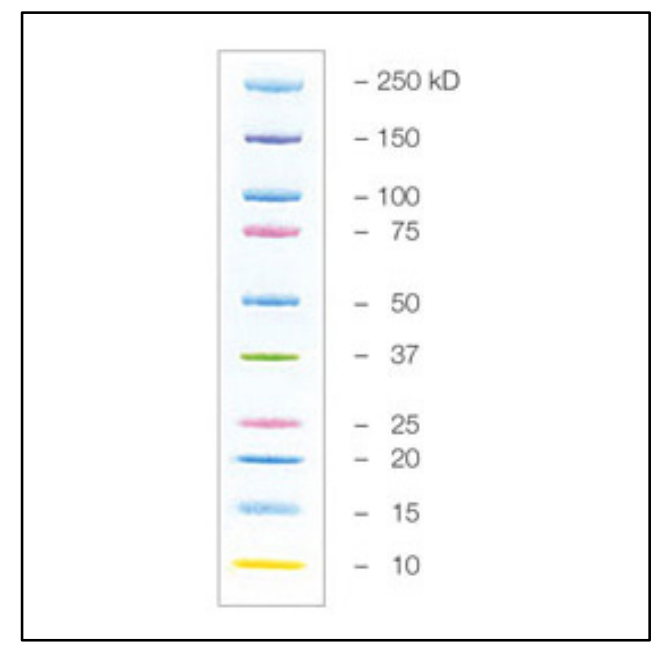

Figure 8. Precision Plus Protein Kaleidoscope Protein Ladder.

\subsection{Western Blot}

Protein samples were resolved on SDS-PAGE gels (Invitrogen) and transferred onto a nitrocellulose membrane (Bio-Rad), by conducting transfer for $1 \mathrm{~h}$ at $100 \mathrm{~V}$ in Transfer Buffer (25 mM Tris Base, 190 mM Glycine and 20\% Methanol). Membrane was stained by Ponceau S solution (SIGMA) for $5 \mathrm{~min}$ and visualized and then was washed with distilled water. The membrane was blocked with 5\% skim milk powder in PBS-Tween $\{0.05 \%(\mathrm{v} / \mathrm{v})$ Tween-20 in PBS. The membranes were probed with mAb 6xHis Antibody (BD Cat: 51-9000012) primary antibody followed by Anti-Mouse IgG-AP conjugated secondary antibody (Sigma Cat: A4312). The reactions were developed using alkaline phosphatase substrate (Bio-Rad Cat. \#170-6432). 


\section{CHAPTER 4}

\section{RESULTS}

The mutants in the W83 strain of Porphyromonas gingivalis were generated by double crossover recombination using suicide plasmids that contained a fragment of a gene of interest ("upstream") followed by an antibiotic resistance gene and a “downstream” region below the PG_RS06260, or PG_RS01820, or PG_RS01060 gene. Briefly, appropriate DNA fragments were directionally cloned adjacent to the ampicillin or erythromycin resistance cassettes (cepA, ermAermFM) yielding master plasmids. Then short oligonucleotides encoding for the hexahistidine motif were inserted into the coding region of chosen genes within the master plasmids. Final constructs were introduced into $P$. gingivalis cells via electroporation. Mutated $P$. gingivalis strains were then used to purify 6-HIS tagged proteins of interest. A detailed description of experiments is presented below.

\subsection{Construction of the PG_RS06260 master plasmid.}

The PG_RS06260 master plasmid - pAG3, was constructed using the suicide vector pAL7 containing the cepA cassette encoding for ampicillin resistance expressed in P. gingivalis cells. Plasmid pAG3 was constructed in a stepwise manner as follows. An "upstream" fragment of DNA (999 bp) containing part of the PG_RS06260 gene was 
amplified from W83 genomic DNA by PCR with primers PG_RS_06260_EcoRI and PG_RS_06260_SmaI (see Table 3). Primer extensions on the 5' side contained recognition sites for EcoRI and SmaI restriction enzymes, which were used for cloning into pAL7 (4192 bp) digested with these two restriction enzymes. A resulting plasmid was denoted as pAG2 (5148 bp). Then a "downstream" fragment (861 bp) was amplified using PG_RS_06255_XbaI and PG_RS_06255_HindIII primers and cloned into pAG2. Both DNA molecules were digested with XbaI and HindIII (sites present within primers and the plasmid). A resulting master plasmid was designated pAG3 and its proper construction was confirmed by sequencing. Figure 9 presents a schematic view of pAG3 construction. 


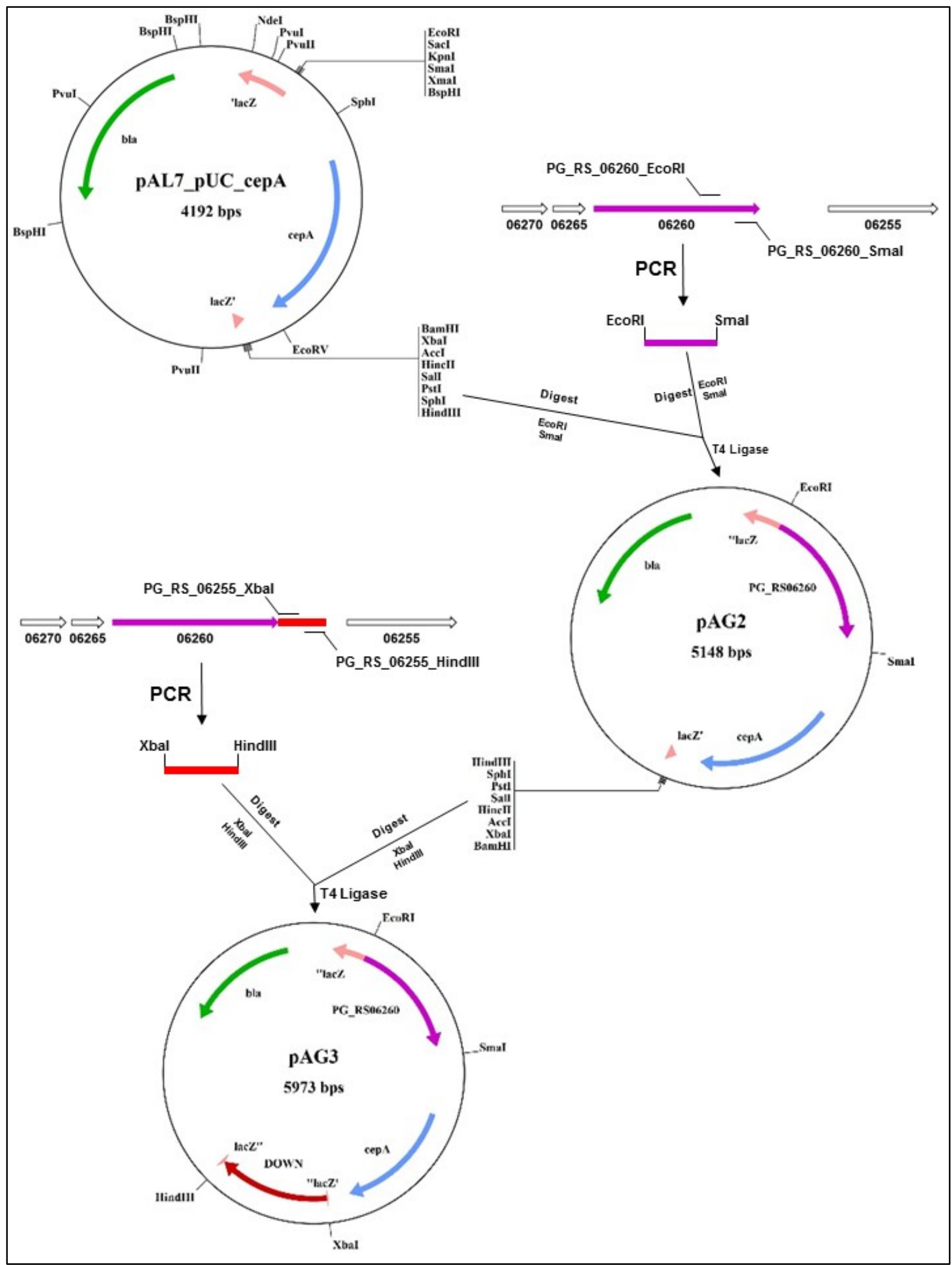

Figure 9. Schematic view of construction of the PG_RS06260 master plasmid pAG3. Genetic manipulations (insertions of DNA fragments) fragmented the lac $Z$ gene and its remnants are marked in the plasmid map. 


\subsection{Construction of PG_RS01820 master plasmid.}

Using a similar method to the PG_RS06260 plasmid construction described above, a section of the PG_RS01820 gene (1010 bp) was amplified using PG_RS01820_SacI and PG_RS1820_SmaI primers and cloned into the pAL7 vector via SacI and SmaI sites to result in the pAG4 (5180 bp) plasmid. Next, a "downstream" region of the gene was amplified (946 bp) using PG_RS01825_XbaI and PG_RS01825_HindIII primers and ligated into pAG4 at XbaI and HindIII sites to complete the master pAG5 (6090 bp) construct (Figure 10). Its proper construction was confirmed by sequencing.

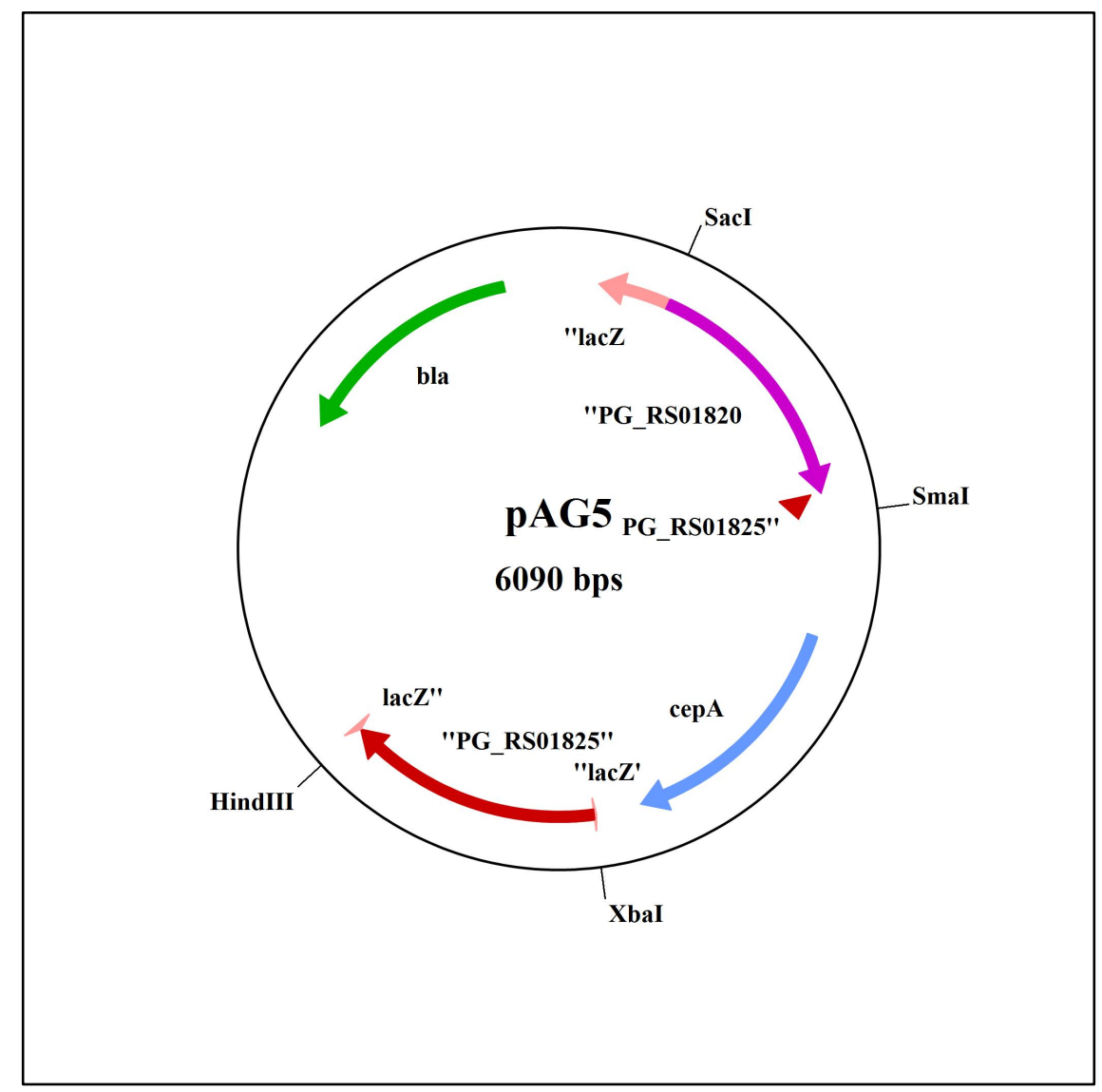

Figure 10. Schematic view of the master plasmid pAG5 (for gene PG_RS01820). Genetic manipulations (insertions of DNA fragments) fragmented the $l a c \bar{Z}$ gene and its remnants are marked in the plasmid map. 


\subsection{Construction of PG_RS01060 master plasmid}

The master plasmid for PG_RS01060 was prepared as described above and kindly provided by Dr. Ky-Anh Nguyen (University of Sydney, Australia). A schematic view of the master plasmid pCpgCeB (for gene PG_RS01060) is shown in Figure 11.

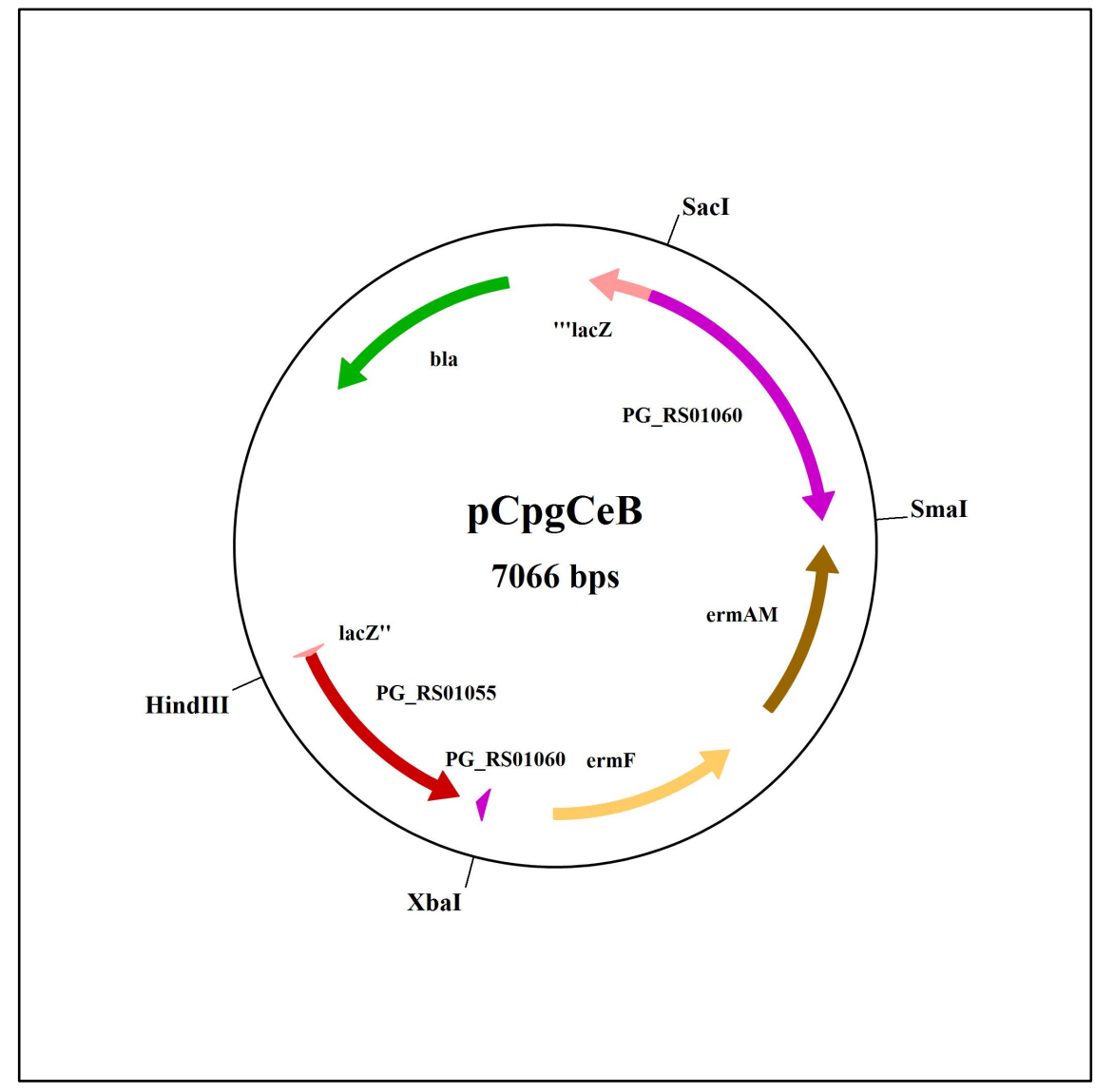

Figure 11. Schematic view of the master plasmid pCpgCeB (for gene PG_RS01060) Genetic manipulations (insertions of DNA fragments) fragmented the lacZ gene and its remnants are marked in the plasmid map. 


\subsection{Site-directed mutagenesis of the master plasmids (hexahistidine tag insertions).}

Using a Phusion site-directed mutagenesis method (Materials and Methods 3.11), various mutants were constructed using the pAG3 (PG_RS06260), pAG5 (PG_RS01820) and pCpgCeB (PG_RS01060) master plasmids as the templates. This method was employed to insert a hexahistidine tag at various locations indicated by a numbered residue after which insertion occurred (Table 7). In Periodontain and CPG70 the insertion was engineered upstream the predicted (green font) or determined (blue font) CTD cleavage site $(\&)$ by $P$. gingivalis sortase (PorU), respectively. In the case of $\mathrm{C} 25$ Peptidase, due to uncertainty in a predicted sortase cleavage site, the His-tag was inserted in two sites separated by 7 residues. E. coli clones were selected on LB agar plates containing ampicillin and erythromycin. Then plasmids were isolated and screened for the correct mutation by DNA sequencing of the pertinent region followed by full plasmid sequencing of HIS-tagged clones.

Table 7. Six Histidines Insertion Site in plasmids.

\begin{tabular}{|c|c|c|c|}
\hline $\begin{array}{l}\text { Protein } \\
\text { (Gene) }\end{array}$ & $\begin{array}{l}\text { Master } \\
\text { plasmid }\end{array}$ & Site & Primers* \\
\hline \multirow[t]{2}{*}{$\begin{array}{l}\text { Periodontain } \\
\left(\mathrm{PG}_{-} \mathrm{RS} 06260\right)\end{array}$} & \multirow[t]{2}{*}{$\mathrm{pAG} 3$} & $\ldots$ TVKIVNG ${ }^{760}$ TAVE \& AIE... & $\begin{array}{l}\text { PG_06260_G760_Rev1 } \\
\text { PG_06260_G760_Fwd2 }\end{array}$ \\
\hline & & $\ldots$...KIVNGT ${ }^{761}$ AVE $\&$ AIES... & $\begin{array}{l}\text { PG_06260_T761_Rev1 } \\
\text { PG_06260_T761_Fwd2 }\end{array}$ \\
\hline \multirow[t]{2}{*}{$\begin{array}{l}\text { C25 Peptidase } \\
\left(\mathrm{PG} \_\mathrm{RS} 01820\right)\end{array}$} & \multirow[t]{2}{*}{ pAG5 } & ...PPLECNK ${ }^{1191} \mathbf{S} \&$ SLDKS... & $\begin{array}{c}\text { M1_Fwd } \\
\text { 6xHis_M1 Rev }\end{array}$ \\
\hline & & 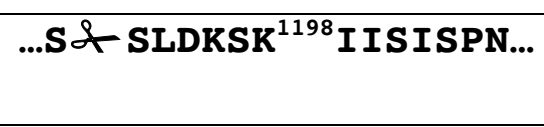 & $\begin{array}{c}\text { 6xHis_M2_Fwd } \\
\text { M2_Rev }\end{array}$ \\
\hline $\begin{array}{c}\text { CPG70 } \\
(\text { PG_RS01060) }\end{array}$ & pCpgCeB & ...IEVILDD ${ }^{738}$ SVE \& DIVA... & $\begin{array}{l}\text { PG_RS01060_i_D738_RevB } \\
\text { PG_RS01060_nt_D738_FwdC }\end{array}$ \\
\hline
\end{tabular}

* For sequence see Table 6 under Material and Methods. 


\subsection{Generation of isogenic mutants via homologous recombination.}

Allele exchange between mutated suicide plasmids and W83 P. gingivalis chromosome was achieved by the electroporation method. Clones obtained on selective plates (ampicillin or erythromycin), were checked for proper genomic modification by PCR followed by DNA sequencing (Table 8). Figure 12 shows exemplary confirmation of the 6-HIS tag insertion into the PG_RS06260 gene in the P. gingivalis chromosome (strain AG002). Selected mutants were later fully sequenced in the region that was altered by homologous recombination.

The obtained mutant strains bearing genes PG_RS01820, PG_RS01060, and PG_RS06260 (encoding C25 peptidase, Carboxypeptidase /CPG70, and Periodontain, respectively) modified with the insertion of the hexahistidine coding sequential motive yielded black-pigmented colonies on the blood agar. This suggests that modifications did not affect secretion of gingipains and hem binding proteins by T9SS, which are essential for $P$. gingivalis pigmentation. The intact function of T9SS was further confirmed by showing that mutant strains expressed the same level of gingipains activity as the parental strain W83 (results not shown).

Table 8. Mutants via homologous recombination.

\begin{tabular}{|c|c|c|}
\hline Protein (Gene) & Site & Mutant name \\
\hline \multirow{2}{*}{$\begin{array}{l}\text { Periodontain } \\
\left(P G \_R S 06260\right)\end{array}$} & ...TVKIVNG ${ }^{760}$ HHHHHHTAVEAIE... & AG002 \\
\hline & ...VKIVNGT ${ }^{761}{ }_{\text {HHHHHHAVEAIES... }}$ & AG003 \\
\hline \multirow{2}{*}{$\begin{array}{l}\text { C25 peptidase } \\
\text { (PG_RS01820) }\end{array}$} & ...PPLECNK ${ }^{1191}$ HHHHHHSSLDKS... & AG004 \\
\hline & ...SSLDKSK ${ }^{1198}$ HHHHHH I ISISPN... & AG005 \\
\hline $\begin{array}{c}\text { CPG70 } \\
(\mathrm{PG} / \mathrm{RS} 01060)\end{array}$ & ...IEVILDD ${ }^{738}{ }_{\text {HHHHHHSVEDIVA... }}$ & AG006 \\
\hline
\end{tabular}




\section{Figure 12. Alignment of sequences of W83 vs AG002 (a fragment).}

AG244_H09 shows the results obtained from sequencing being compared to W83 fragment (06260 G760). Insertion of DNA fragment encoding for $6 \times \mathrm{His}$ (CATCACCATCACCATCAC) in the AG002 genome is highlighted.

\subsection{Confirmation of expression of His-tagged recombinant proteins in $P$. gingivalis cells and batch purification.}

Expression of recombinant proteins was confirmed using Western-blot analysis with specific monoclonal anti-6xHis antibodies. All five generated $P$. gingivalis mutants (AG002-AG006) were grown in liquid cultures and then 3 separate fractions were resolved by SDS-PAGE and subjected to Western-blot. The fractions analyzed were: cell pellet, culture media, and proteins concentrated from media by acetone precipitation. In addition, samples of the $P$. gingivalis W83 wild-type strain were also probed serving as a negative control. Western blotting with anti-6xHis mAbs revealed the expected specific reaction in all the samples of the AG006 strain expressing CPG70-6xHis from the modified PG_RS01060 gene. Unfortunately, no reaction was observed in case of other mutants (Figure 13). 


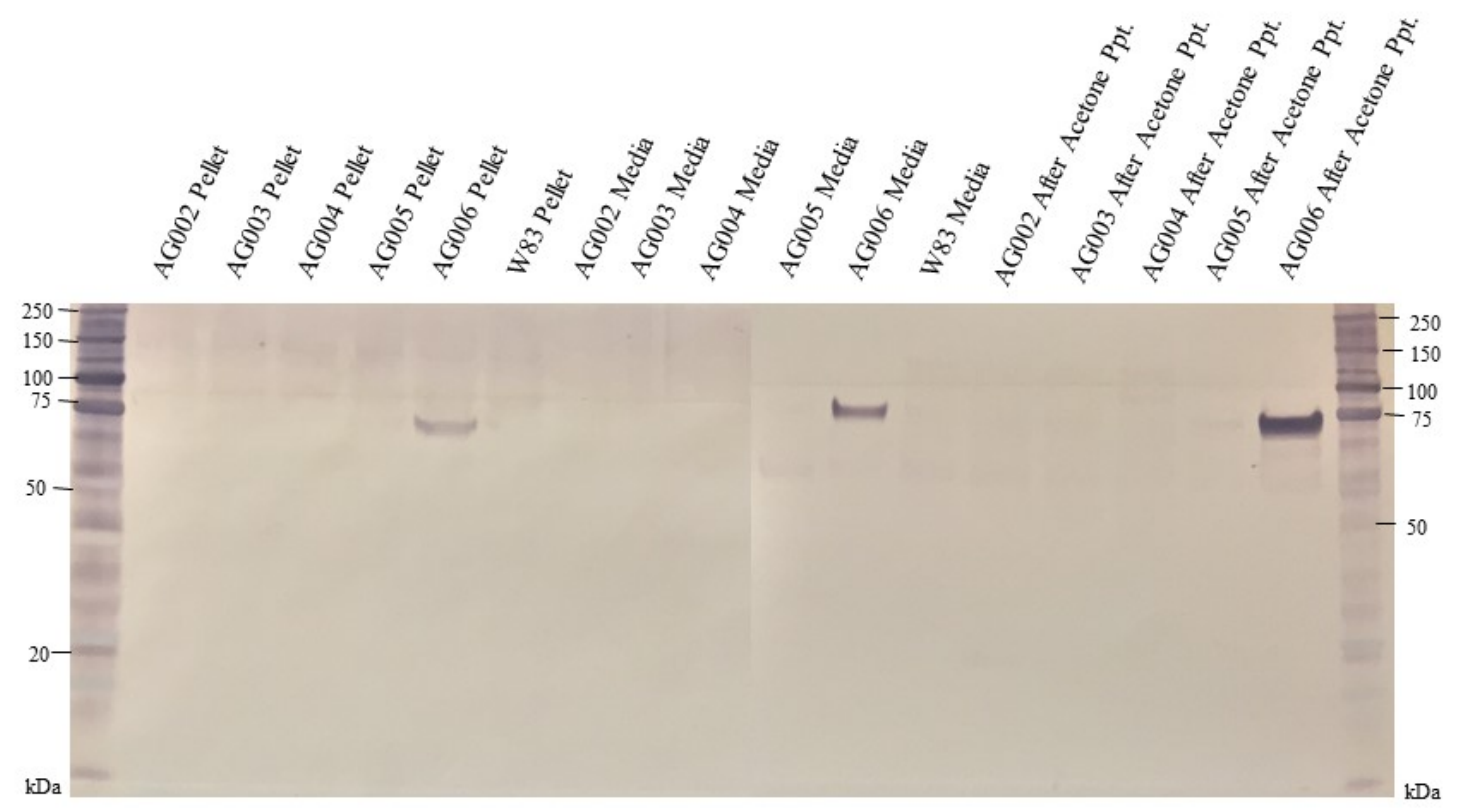

Figure 13. Western-blot analysis of fractions obtained from $P$. gingivalis AG002AG006 cultures theoretically expressing His-tagged Periodontain (AG002 and AG003), C25 peptidase (AG004 and AG005) and CPG70 (AG006).

Protein fractions (pelleted cells, culture media and media after acetone precipitation) were separated on 4-12\% BIS-Tris gel, transferred onto nitrocellulose and developed with anti-6HIS mAbs. Protein molecular weight standards are indicated on the sides of the membranes.

Because of the negative result of the initial analysis, which may be due to low expression level of Periodontain and C25 peptidase, acetone precipitate growth media were subjected to a batch affinity chromatography step for 6xHis tagged proteins using Nickel-Sepharose affinity matrix. Proteins bound to the matrix were eluted with $500 \mathrm{mM}$ imidazole, concentrated 100x (from $20 \mathrm{ml}$ ) and again resolved by SDS-PAGE $(50 \mu \mathrm{l})$ and probed with anti-6xHis mAbs. The analysis confirmed the presence of the hexahistidine tagged CPG70 in the sample obtained from AG006 (PG_RS01060) and revealed that also AG002 and AG003 (both carrying the modified PG_RS06260 gene encoding Periodontain) expressed a $6 x$ His labeled protein, which apparently was enriched due to 
an affinity chromatography step. Surprisingly, however, molecular mass of circa $20 \mathrm{kDa}$ of the immunoreactive band was much lower than the expected mass (approximately 80 $\mathrm{kDa}$ ) of intact Periodontain indicating that the protein was subjected to proteolysis. No positive reaction was observed for AG004 and AG005 (both carrying the modified PG_RS01820 gene and encoding C25 peptidase) (Figure 14).

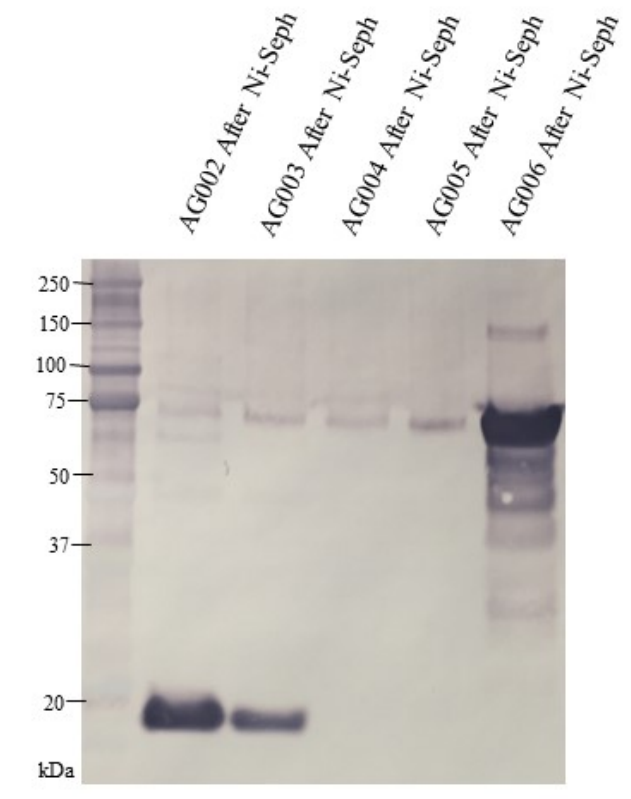

Figure 14. Western-blot analysis of elution samples obtained after purification of AG002 and AG003 (Periodontain), AG004 and AG005 (C25 peptidase), and AG006 (CPG70) from culture media of the mutant strains of $P$. gingivalis.

Proteins eluted from Ni-Sepharose matrix with $500 \mathrm{mM}$ imidazole, concentrated 100x and separated on $4-12 \%$ BIS-Tris gel. Resolved samples were then transferred onto nitrocellulose and developed with anti-6HIS mAbs. Protein molecular weight standards are indicated on the left side of the membrane. 


\subsection{Purification of $P$. gingivalis His-tagged proteins.}

To obtain larger amount of CPG70-6xHis and Periodontain-6xHis proteins the mutant strains expressing these proteins were cultivated to stationary phase of growth in $200 \mathrm{ml}$, and then proteins were acetone-precipitated from cell-free growth medium. Although no His-tagged C25 peptidase was detected in media of AG004 and AG005, they were also subjected to the same procedure.

Acetone-precipitated proteins from all constructed mutants (AG002-AG006) and the W83 wild-type strain were processed through full purification procedure applying DE-52 anion-exchange matrix for pre-purification step followed by a use of Ni-Sepharose. HIS-tagged proteins bound to the resin were eluted in a single step with $500 \mathrm{mM}$ imidazole. Thereafter, eluates were concentrated (100x) and $50 \mu \mathrm{l}$ were run on a SDS-PAGE. Resolved proteins were visualized by SimplyBlue Safe Stain (Figure 15). Analysis showed that proteins purified in this way from growth media of the AG002 and AG003 strains is composed of two polypeptide chains of approximately $52 \mathrm{kDa}$ and 20 $\mathrm{kDa}$. The Western-blot analysis using anti-6HIS antibodies (Figure 14) revealed the $20 \mathrm{kDa}$ band immunoreactive with antibodies, indicating this band represents the Cterminal part of Periodontain with the hexahistidine tag. Apparently, the $52 \mathrm{kDa}$ band represents N-terminal part of the Periodontain molecule, which is non-covalently associated with the $20 \mathrm{kDa}$ domain, as described for Periodontain purified from P. gingivalis strain HG66 [42].

The $70 \mathrm{kDa}$ protein was purified from AG006 (PG_RS01060 gene encoding CPG70) (Figure 15) and the western blot analysis confirmed the presence of the 6xHis tag. The molecular mass corroborates with predicted mass of CPG70 minus the CTD. 


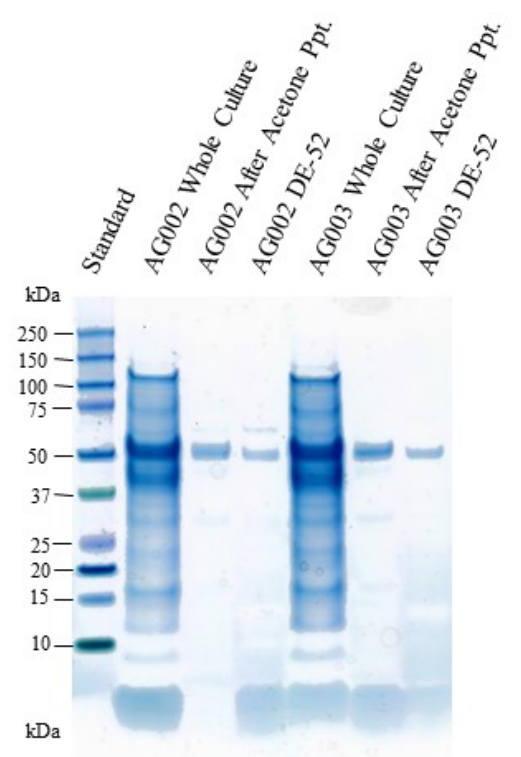

PERIODONTAIN

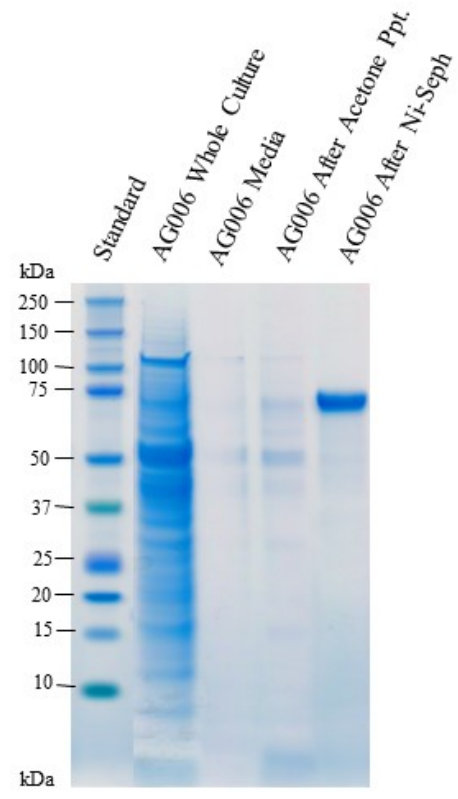

CPG70

(A)

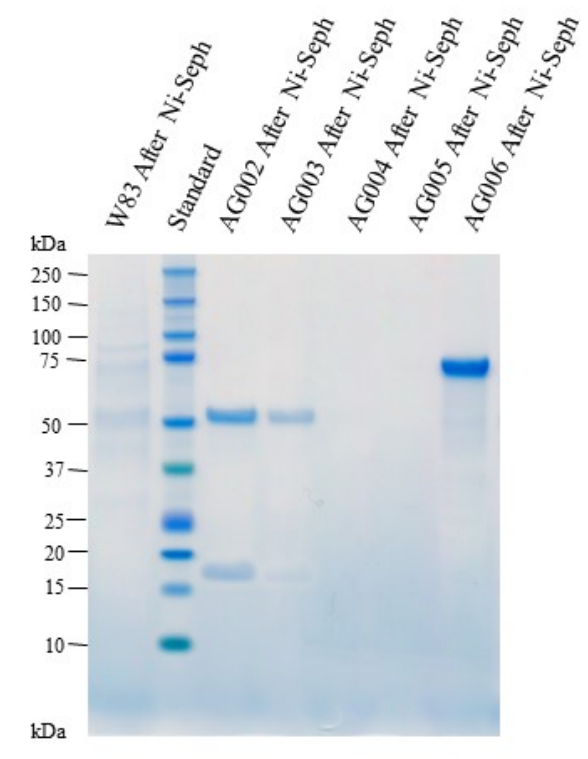

(B)

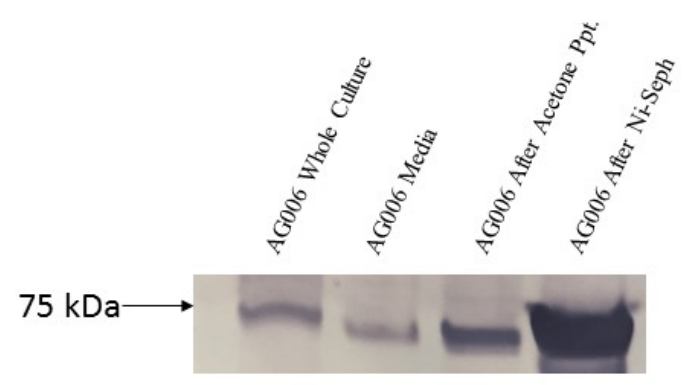

(C) 
Figure 15. SDS-PAGE and Western Blots analyses of full purification process for AG002 and AG003 (Periodontain), AG004 and AG005 (C25 peptidase), and AG006 (CPG70) strains of $P$. gingivalis.

Proteins were first purified on DE-52 matrix, then applied on Ni-Sepharose resin and eluted with $500 \mathrm{mM}$ imidazole. 100x concentrated samples from all purification steps (whole culture, medium after acetone precipitation, sample after DE-52, and sample after Ni-Sepharose) were separated on $4-12 \%$ BIS-Tris gel and then transferred onto nitrocellulose and developed with anti-6HIS $\mathrm{mAbs}$. Protein molecular weight standards are indicated on the left side of gels/membranes.

(A) SDS-PAGE analysis of samples from consecutive purification steps (whole culture, growth media, acetone-precipitated media and after DE-52 and after Ni-Sepharose) of Periodontain and CPG70 (B) SDS-PAGE analysis of proteins from growth media of indicated strains after the final step of purification (Ni-Sepharose) (C) Western-Blot analysis CPG70-6xHis after consecutive steps of purification.

Samples obtained from AG003 and AG004 strains (PG_RS01820 gene encoding C25 peptidase) were negative and didn't reveal any purified proteins. 


\section{CHAPTER 5}

\section{DISCUSSION}

Recent studies of T9SS of $P$. gingivalis, revealed the role played by the C-terminal domain (CTD) in secreted protein maturation and translocation across the outer membrane (OM). The CTD in gingipains and other proteins of $P$. gingivalis (such as PPAD- Peptidylarginine deiminase) are found to act as the recognition signal for directing these proteins to the T9SS machinery and thus leading to an OM export pathway [33]. With the focus on RgpB, as the model cargo protein of this system, removal of its last 2 residues at the C-terminal of the CTD resulted in failure of $\mathrm{RgpB}$ to process and export across the OM, and partially processed RgpB was found in periplasm, suggesting that C-terminal motif plays an important role in the post-translational modification of cargo proteins [33]. RgpB, in a process of maturation, undergoes modification at various steps. The signal peptide is cleaved during the export to periplasm across the inner membrane via Sec pathway. In the periplasm, an N-terminal pro-domain is processed followed by the CTD removal through T9SS machinery during translocation of the OM. This leads to secretion of the 48-kDa soluble form of RgpB (Figure 5) [26, 43]. However, it was also found in many strains of $P$. gingivalis that the majority of mature $\mathrm{RgpB}$ exist as a diffuse $70-90 \mathrm{kDa}$ band (Figure 5) due to modification with A-LPS. This type of the OM-associated gingipain is 
referred to as membrane type $\operatorname{RgpB}(\mathrm{mt}-\mathrm{RgpB})$ [40]. It is now generally accepted that ALPS modification is responsible for the anchoring of RgpB and other T9SS cargo proteins to the outer membrane. It is suggested through studies that CTD played an essential role for the secretion of RgpB across the OM, as well as glycosylation [44]. Structurally, RgpB which possesses N-terminal signal, a pro-peptide domain, a catalytic domain containing caspase-like and immunoglobulin-like subdomains (IgLD), and a C-terminal domain (CTD) (Figure 5) [45]. It became important to know the role of the IgLD, which precedes the CTD and also the junction between the IgLD and CTD in the maturation and translocation of the protein across the cell membrane. It was found that the glycosylation of the mature RgpB was interrupted when the IgLD-CTD junction was modified and mt-RgpB was absent or reduced in such strains [40].

Similarly to RgpB, another enzyme from $P$. gingivalis, referred to as PPAD (with known structure), also possesses the immunoglobulin-like domain (IgLD) directly followed by the CTD, and is secreted across the OM via T9SS [46]. As shown for RgpB, when hexahistidine (6xHis) were inserted into the IgLD side of the junction, just upstream of the CTD, the mature, soluble form of $\mathrm{RgpB}$ of $48 \mathrm{kDa}$ was detected by the western blot (anti RgpB) in the growth media with minimal or no diffuse band of RgpB associated with cells. The soluble RgpB retained the polyhistidine tags as visualized on anti 6xHis western blot [40]. This indicates that RgpB with the polyhistidine tag didn't undergo modifications with A-LPS post-translationally. Later, polyhistidine tagged recombinant RgpB was purified in the soluble, mature form bearing the polyhistidine tag through nickel-chelating affinity chromatography which was indistinguishable from the 
native RgpB enzyme [47]. Same experiments when carried out with PPAD also yielded the pure protein in the soluble, mature form.

To verify the concept that insertion of hexahistidine upstream of the CTD in other T9SS cargo proteins will lead to secretion of the A-LPS-free protein, we applied the same approach to four different $P$. gingivalis proteins with the predicated CTDs [35]. Two of these proteins, including CPG70 (PG_RS01060) and periodontain (PG_RS06260), were predicted with the high degree of confidence to possess $\beta$-strand structures typical for the IgLD and preceding the CTD as shown in PPAD and gingipains (check Appendix) (http://toolkit.tuebingen.mpg.de/sections/secstruct). On the other hand, both C25 Peptidase (PG_RS01820) and HBP 35 (PG_RS02720) seem to lack IgLD domain. The work with HBP 35 is still undergoing and is not referred further. The hexahistidine tags were inserted just upstream of the predicted CTD cleavage sites. The specific mutations were done in the wild-type strain of $P$. gingivalis (W83) and the W83 strain was considered as the negative control for our experiments. The mutants grown to the stationary phase and cell-free growth media were subjected to batch purification through nickel-sepharose affinity chromatography. In this way, we were able to purify AG002 and AG003 (Periodontain), and AG006 (CPG70) bearing hexahistidine tag from the media in the soluble form.

As mentioned earlier gingipains are modified with the anionic LPS, which in turn provides the attachment to the cell surface. It is to be noted that 30 more proteins which are reported to possess CTD are directed to the cell surface via T9SS and appear to be modified by A-LPS as well, aiding in their attachment to the cell surface and forming electron dense surface layer (EDSL) with gingipains being in majority [35, 48]. 
P. gingivalis is found to produce outer membrane vesicles (OMVs), which are basically composed of single membrane derived from OM and contains OM proteins and LPS [48]. OMVs are considered to play an important role in the virulence through bacterial adherence, acting against host defence and delivering the wide range of toxins. So, gingipains and other T9SS cargo proteins, which form OMVs [48], have been suggested to play the role in virulence as well. Experimentally, it has been found that 15 of 30 CTD bearing proteins are present in the outer membrane fractions along with the gingipains [48]. Periodontain, a CTD bearing cargo proteins, which have been shown to be present in the $P$. gingivalis OMV [48] was characterized earlier and have been shown to be capable of inactivating the human serpin, $\alpha$-1-proteinase inhibitor, the primary endogenous regulator of human neutrophil elastase, suggesting its role in the virulence [42]. It was shown in earlier purification from $P$. gingivalis HG66 strain that periodontain showed up two bands on SDS-PAGE analysis, one band of approximately $50 \mathrm{kDa}$ and another approximately $20 \mathrm{kDa}$, which suggested that it exists as a heterodimer [42]. Similarly, purification of 6xHis-periodontain showed two bands of approximately same sizes (Figure 15a) but the lower band showed positive reaction when probed with specific 6xHis antibody (Figure 14), suggesting a large catalytic domain (approx. $50 \mathrm{kDa}$ ) and the small terminal domain located towards $\mathrm{C}$ terminal with His tag (approx. $20 \mathrm{kDa}$ ). CPG 70, which have been reported to play an important role in the virulence of the organism and also involved in posttranslational processing of gingipains, was found in the outer membrane fractions as well, which was purified with the approximate calculations of molecular mass close to $70 \mathrm{kDa}$, as expected [48-50]. Another important OMV, HBP35 was found to play an important role in the binding of hem that is 
considered to be an essential component for the survival of $P$. gingivalis [51]. C25 Peptidase could not be detected with anti-6xHis Abs neither in growth medium nor in the cell extract. This can be explained either by such processing of the modified protein that the $6 x$ His tag is lost or the level of expression is very low. The latter option is supported by the fact that $\mathrm{C} 25$ Peptidase was not detected in the proteomic analysis of $\mathrm{OM}$ and OMV [48]. C25 peptidase seems to be lacking the IgLD like structure (check appendix) and it would be interesting to find more about this hypothetical protein. Any further work, extended by placing polyhistidine tags at various other positions needs to be preceded by a qRT-PCR analysis of the PG_RS01820 gene expression.

In conclusion, obtained results clearly confirmed our hypothesis that insertion of the hexahistidine tag in front of the CTD in T9SS cargo proteins leads to the secretion of mature and soluble proteins into the growth media facilitating their purification. We expect that in this way most of the T9SS secreted proteins can be obtained in large amounts in highly purified forms needed for structural and functional studies. The failure to express C25 peptidase with the His-tag is due to the lack of this protein expression as shown in the proteomic studies described by Vieth et al. [48].

In general, cumulative findings indicate the importance of CTD-mediated secretion of the proteins in a new defined secretory mechanism (T9SS) and the roleplayed by the junction of $\beta$-strand structures typical for the IgLD and the CTD. This proves the concept of the research hypothesis and can be used for understanding the mechanism of recognition and processing of CTD bearing cargo proteins that may provide a significant opportunity to impede maturation of these important virulence factors in the treatment of periodontal disease. The present work done would contribute 
to the knowledge of characterizing the nature of the CTD processing site and the role played by these sites on the partitioning of the mature, secreted protein domains. More than 30 predicted CTD bearing cargo proteins of $P$. gingivalis have been reported, of which 15 have been found along with gingipains, associated with the outer membrane of the cell $[35,48]$. It is believed these proteins should have some role to play in the virulence of the organism directly or indirectly. The CTDs have also been found in other members belonging to the Bacteriodetes phylum [33]. There is evidence the processing mechanism and membrane attachment is conserved for all CTD-bearing proteins [48]. Thus, the concept mentioned in this work, can prove to be useful for the purification and characterization of other CTD bearing cargo proteins secreted by $P$. gingivalis in order to understand the role of these proteins in the virulence and survival of the organism. Also, this concept can be extended to the studies involving other periodontal pathogens such as Prevotella intermedia and Tannerella forsythia, which have shown evidence for CTD bearing proteins as well as existence of T9SS [35, 48]. It would be a great step forward in the identification and purification of proteins of these organisms and studying their collective role in causing periodontal diseases. 


\section{REFERENCES}

1. Lee, V.T. and O. Schneewind, Protein secretion and the pathogenesis of bacterial infections. Genes Dev, 2001. 15(14): p. 1725-52.

2. Li, N. and C.A. Collyer, Gingipains from Porphyromonas gingivalis - Complex domain structures confer diverse functions. Eur J Microbiol Immunol (Bp), 2011. 1(1): p. 41-58.

3. Natale, P., T. Brüser, and A.J.M. Driessen, Sec- and Tat-mediated protein secretion across the bacterial cytoplasmic membrane-Distinct translocases and mechanisms. Biochimica et Biophysica Acta (BBA) - Biomembranes, 2008. 1778(9): p. 1735-1756.

4. $\quad$ Berks, B.C., The twin-arginine protein translocation pathway. Annu Rev Biochem, 2015. 84: p. 843-64.

5. Gerlach, R.G. and M. Hensel, Protein secretion systems and adhesins: the molecular armory of Gram-negative pathogens. Int J Med Microbiol, 2007. 297(6): p. 401-15.

6. Desvaux, M., et al., Secretion and subcellular localizations of bacterial proteins: a semantic awareness issue. Trends Microbiol, 2009. 17(4): p. 139-45.

7. Delepelaire, P., Type I secretion in gram-negative bacteria. Biochim Biophys Acta, 2004. 1694(1-3): p. 149-61.

8. Costa, T.R., et al., Secretion systems in Gram-negative bacteria: structural and mechanistic insights. Nat Rev Microbiol, 2015. 13(6): p. 343-59.

9. Korotkov, K.V., M. Sandkvist, and W.G. Hol, The type II secretion system: biogenesis, molecular architecture and mechanism. Nat Rev Microbiol, 2012. 10(5): p. 336-51.

10. Tseng, T.T., B.M. Tyler, and J.C. Setubal, Protein secretion systems in bacterialhost associations, and their description in the Gene Ontology. BMC Microbiol, 2009. 9 Suppl 1: p. S2.

11. Schraidt, O. and T.C. Marlovits, Three-dimensional model of Salmonella's needle complex at subnanometer resolution. Science, 2011. 331(6021): p. 1192-5.

12. Cornelis, G.R., The type III secretion injectisome. Nat Rev Microbiol, 2006. 4(11): p. 811-25.

13. Buttner, D., Protein export according to schedule: architecture, assembly, and regulation of type III secretion systems from plant- and animal-pathogenic bacteria. Microbiol Mol Biol Rev, 2012. 76(2): p. 262-310.

14. Christie, P.J. and E. Cascales, Structural and dynamic properties of bacterial type IV secretion systems (review). Mol Membr Biol, 2005. 22(1-2): p. 51-61.

15. Trokter, M., et al., Recent advances in the structural and molecular biology of type IV secretion systems. Curr Opin Struct Biol, 2014. 27: p. 16-23. 
16. Leo, J.C., I. Grin, and D. Linke, Type V secretion: mechanism(s) of autotransport through the bacterial outer membrane. Philos Trans R Soc Lond B Biol Sci, 2012. 367(1592): p. 1088-101.

17. Leyton, D.L., A.E. Rossiter, and I.R. Henderson, From self sufficiency to dependence: mechanisms and factors important for autotransporter biogenesis. Nat Rev Microbiol, 2012. 10(3): p. 213-25.

18. Junker, M., R.N. Besingi, and P.L. Clark, Vectorial transport and folding of an autotransporter virulence protein during outer membrane secretion. Mol Microbiol, 2009. 71(5): p. 1323-32.

19. Basler, M., et al., Type VI secretion requires a dynamic contractile phage taillike structure. Nature, 2012. 483(7388): p. 182-6.

20. Ates, L.S., E.N. Houben, and W. Bitter, Type VII Secretion: A Highly Versatile Secretion System. Microbiol Spectr, 2016. 4(1).

21. Goyal, P., et al., Structural and mechanistic insights into the bacterial amyloid secretion channel CsgG. Nature, 2014. 516(7530): p. 250-3.

22. Mysak, J., et al., Porphyromonas gingivalis: major periodontopathic pathogen overview. J Immunol Res, 2014. 2014:476068.

23. Pike, R., et al., Lysine- and arginine-specific proteinases from Porphyromonas gingivalis. Isolation, characterization, and evidence for the existence of complexes with hemagglutinins. J Biol Chem, 1994. 269(1): p. 406-11.

24. Pavloff, N., et al., Molecular cloning and characterization of Porphyromonas gingivalis lysine-specific gingipain. A new member of an emerging family of pathogenic bacterial cysteine proteinases. J Biol Chem, 1997. 272(3): p. 1595600.

25. Pavloff, N., et al., Molecular cloning and structural characterization of the Arggingipain proteinase of Porphyromonas gingivalis. Biosynthesis as a proteinase-adhesin polyprotein. J Biol Chem, 1995. 270(3): p. 1007-10.

26. Sato, K., et al., A protein secretion system linked to bacteroidete gliding motility and pathogenesis. Proc Natl Acad Sci U S A, 2010. 107(1): p. 276-81.

27. de Diego, I., et al., The outer-membrane export signal of Porphyromonas gingivalis type IX secretion system (T9SS) is a conserved C-terminal betasandwich domain. Sci Rep, 2016. 6: p. 23123.

28. Sato, K., et al., Identification of a new membrane-associated protein that influences transport/maturation of gingipains and adhesins of Porphyromonas gingivalis. J Biol Chem, 2005. 280(10): p. 8668-77.

29. Nakayama, K., Porphyromonas gingivalis and related bacteria: from colonial pigmentation to the type IX secretion system and gliding motility. J Periodontal Res, 2015. 50(1): p. 1-8.

30. Saiki, K. and K. Konishi, Identification of a Porphyromonas gingivalis novel protein sov required for the secretion of gingipains. Microbiol Immunol, 2007. 51(5): p. 483-91.

31. Kadowaki, T., et al., A two-component system regulates gene expression of the type IX secretion component proteins via an ECF sigma factor. Sci Rep, 2016. 6: p. 23288. 
32. Seers, C.A., et al., The RgpB C-terminal domain has a role in attachment of RgpB to the outer membrane and belongs to a novel C-terminal-domain family found in Porphyromonas gingivalis. J Bacteriol, 2006. 188(17): p. 6376-86.

33. Nguyen, K.A., J. Travis, and J. Potempa, Does the importance of the C-terminal residues in the maturation of RgpB from Porphyromonas gingivalis reveal a novel mechanism for protein export in a subgroup of Gram-Negative bacteria? J Bacteriol, 2007. 189(3): p. 833-43.

34. Gorasia, D.G., et al., Porphyromonas gingivalis Type IX Secretion Substrates Are Cleaved and Modified by a Sortase-Like Mechanism. PLoS Pathog, 2015. 11(9): p. e1005152.

35. Veith, P.D., et al., Protein substrates of a novel secretion system are numerous in the Bacteroidetes phylum and have in common a cleavable C-terminal secretion signal, extensive post-translational modification, and cell-surface attachment. J Proteome Res, 2013. 12(10): p. 4449-61.

36. Sato, K., et al., Identification of Porphyromonas gingivalis proteins secreted by the Por secretion system. FEMS Microbiol Lett, 2013. 338(1): p. 68-76.

37. McBride, M.J. and Y. Zhu, Gliding motility and Por secretion system genes are widespread among members of the phylum bacteroidetes. J Bacteriol, 2013. 195(2): p. 270-8.

38. McBride, M.J. and D. Nakane, Flavobacterium gliding motility and the type IX secretion system. Curr Opin Microbiol, 2015. 28: p. 72-7.

39. Paramonov, N., et al., Structural analysis of a novel anionic polysaccharide from Porphyromonas gingivalis strain W50 related to Arg-gingipain glycans. Mol Microbiol, 2005. 58(3): p. 847-63.

40. Zhou, X.Y., et al., Sequence-independent processing site of the $C$-terminal domain (CTD) influences maturation of the RgpB protease from Porphyromonas gingivalis. Mol Microbiol, 2013. 89(5): p. 903-17.

41. Nelson, K.E., et al., Complete genome sequence of the oral pathogenic Bacterium porphyromonas gingivalis strain W83. J Bacteriol, 2003. 185(18): p. 5591-601.

42. Nelson, D., et al., Purification and characterization of a novel cysteine proteinase (periodontain) from Porphyromonas gingivalis. Evidence for a role in the inactivation of human alpha1-proteinase inhibitor. J Biol Chem, 1999. 274(18): p. 12245-51.

43. Veillard, F., et al., Inhibition of gingipains by their profragments as the mechanism protecting Porphyromonas gingivalis against premature activation of secreted proteases. Biochim Biophys Acta, 2013. 1830(8): p. 4218-28.

44. Slakeski, N., et al., $C$-terminal domain residues important for secretion and attachment of RgpB in Porphyromonas gingivalis. J Bacteriol, 2011. 193(1): p. $132-42$.

45. Potempa, J., et al., Gingipains, the major cysteine proteinases and virulence factors of Porphyromonas gingivalis: structure, function and assembly of multidomain protein complexes. Curr Protein Pept Sci, 2003. 4(6): p. 397-407.

46. Goulas, T., et al., Structure and mechanism of a bacterial host-protein citrullinating virulence factor, Porphyromonas gingivalis peptidylarginine deiminase. Sci Rep, 2015. 5: p. 11969. 
47. Veillard, F., et al., Purification and characterisation of recombinant His-tagged RgpB gingipain from Porphymonas gingivalis. Biol Chem, 2015. 396(4): $\mathrm{p}$. 377-84.

48. Veith, P.D., et al., Porphyromonas gingivalis outer membrane vesicles exclusively contain outer membrane and periplasmic proteins and carry a cargo enriched with virulence factors. J Proteome Res, 2014. 13(5): p. 242032.

49. Chen, Y.Y., et al., CPG70 is a novel basic metallocarboxypeptidase with Cterminal polycystic kidney disease domains from Porphyromonas gingivalis. J Biol Chem, 2002. 277(26): p. 23433-40.

50. Veith, P.D., Y.Y. Chen, and E.C. Reynolds, Porphyromonas gingivalis RgpA and Kgp proteinases and adhesins are $C$ terminally processed by the carboxypeptidase CPG70. Infect Immun, 2004. 72(6): p. 3655-7.

51. Shoji, M., et al., Characterization of hemin-binding protein 35 (HBP35) in Porphyromonas gingivalis: its cellular distribution, thioredoxin activity and role in heme utilization. BMC Microbiol, 2010. 10: p. 152. 


\section{APPENDIX}

Overview of predicted secondary structure feature ( $\beta$-strand structures typical for the $\operatorname{IgLD}$ ) in selected cargo proteins of $P$. gingivalis, in comparison to known proteins with such structures (Kgp and PPAD) (http://toolkit.tuebingen.mpg.de/sections/secstruct).
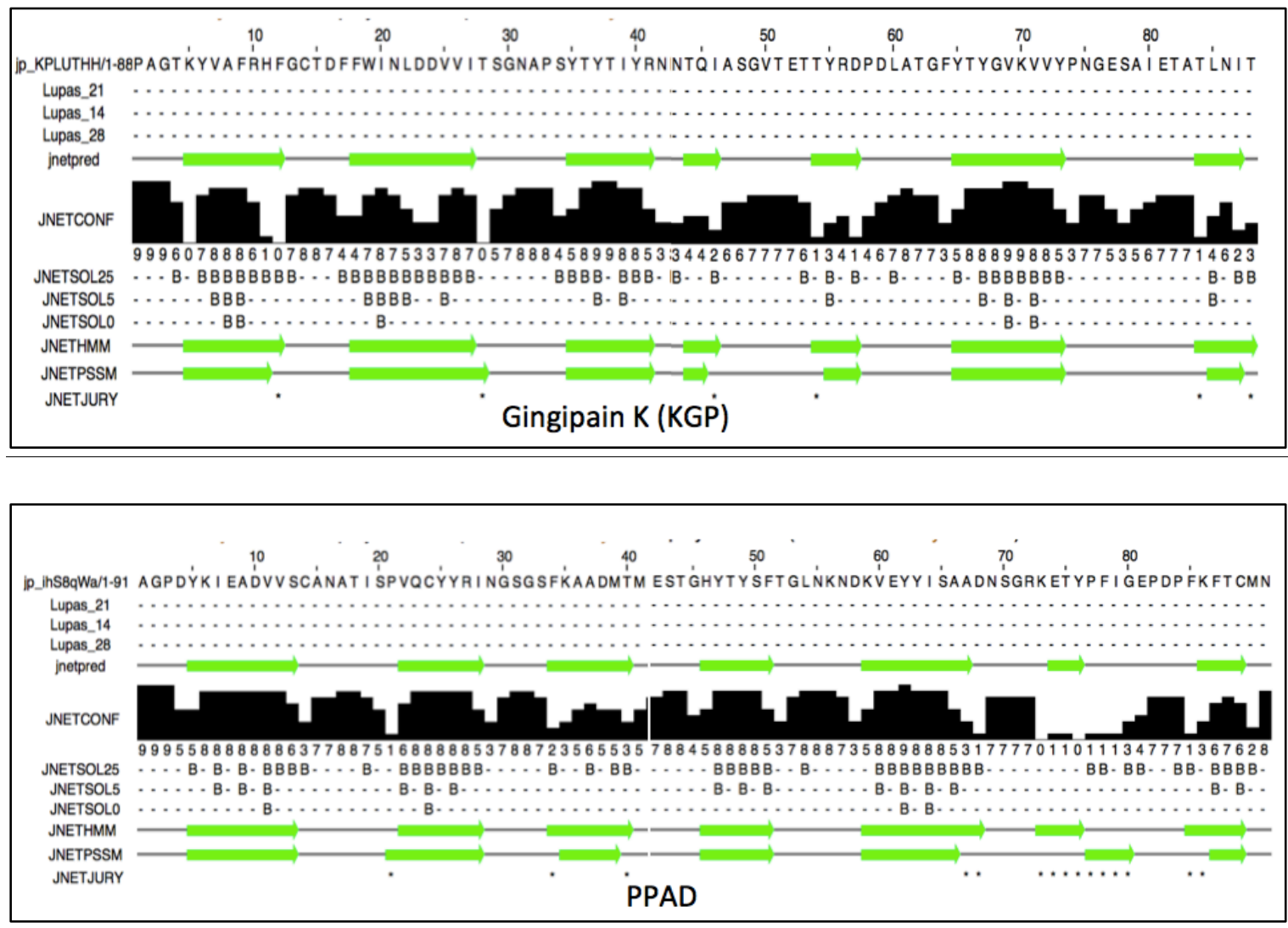

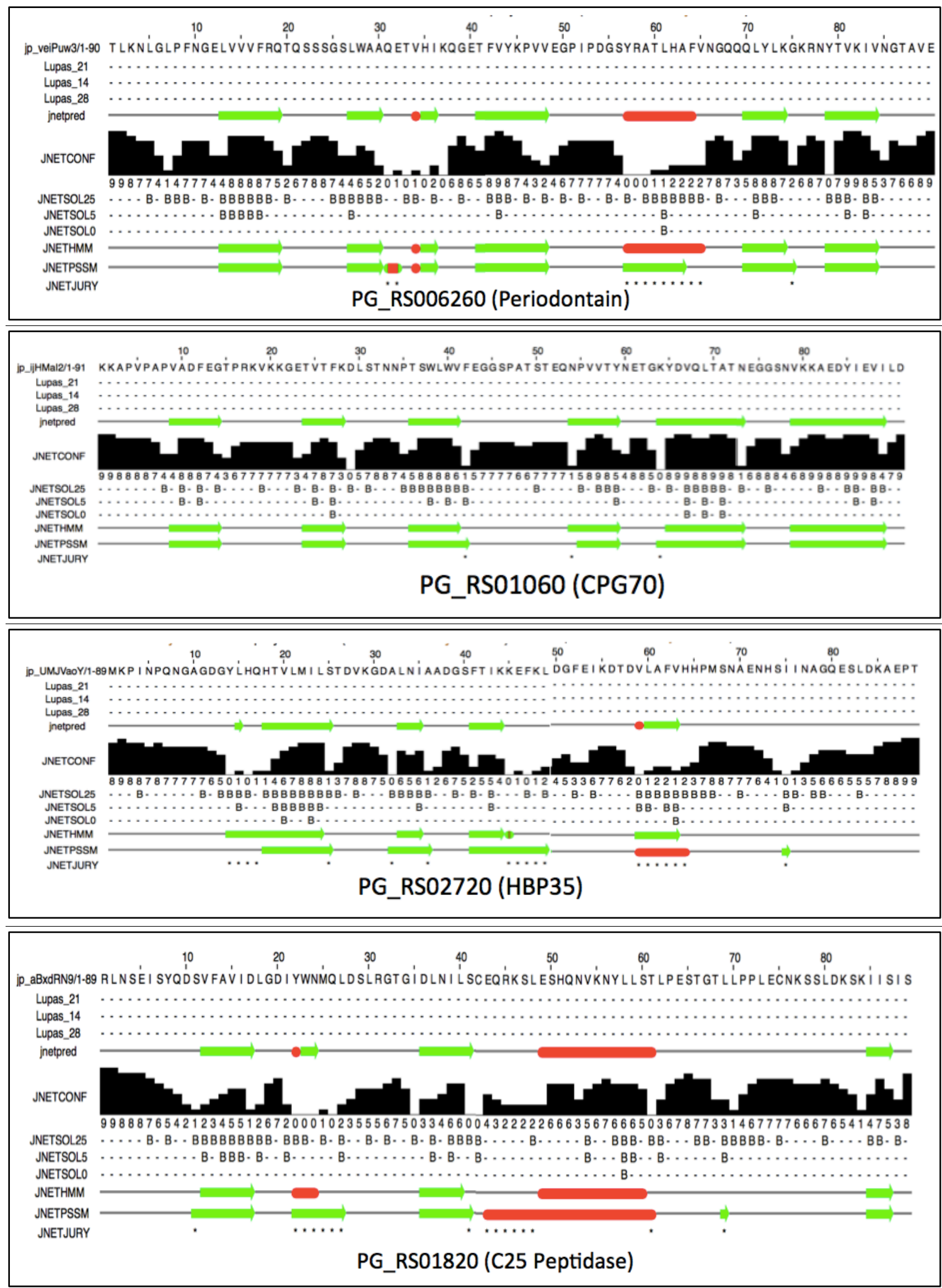


\section{CURRICULUM VITAE}

NAME:

ADDRESS:

EDUCATION

\& TRAINING:

PROFESSIONAL SOCIETIES:

PRESENTATIONS:
Apoorv Goel

Dept. of Oral Immunology and Infectious Disease University of Louisville School of Dentistry

501 S Preston Louisville, KY 40202

Bachelor of Dental Surgery (BDS)

Pt. B.D. Sharma University of Health Sciences (INDIA) $2008-2013$

American Association for Dental Research (AADR)

Jan 2015 - Ongoing

International Association for Dental Research (IADR)

Jan 2015 - Ongoing

National Student Research Group (NSRG)

Jan 2015 - Ongoing

American Dental Association (ADA)

Jan 2014 - Ongoing

The International Association of Student Clinicians American Dental Association (SCADA)

Feb 2013 - Ongoing

Research!Louisville, Louisville, KY

November 2015

Poster Presentation: Purification and Initial

Characterization of T9SS Cargo proteins of $P$. gingivalis

GSC Regional Research Conference, Louisville, KY April 2016

Poster Presentation: Purification and Initial

Characterization of T9SS Cargo proteins of $P$. gingivalis 